\title{
Characterization of Ceramic Foam Filters Used for Liquid Metal Filtration
}

\author{
MARK WILLIAM KENNEDY, KEXU ZHANG, ROBERT FRITZSCH, \\ SHAHID AKHTAR, JON ARNE BAKKEN, and RAGNHILD E. AUNE
}

\begin{abstract}
In the current study, the morphology including tortuosity, and the permeability of 50-mm thick commercially available $30,40,50$, and 80 pores per inch (PPI) alumina ceramic foam filters (CFFs) have been investigated. Measurements have been taken of cell (pore), window, and strut sizes, porosity, tortuosity, and liquid permeability. Water velocities from $\sim 0.015$ to $0.77 \mathrm{~m} / \mathrm{s}$ have been used to derive both first-order (Darcy) and second-order (Non-Darcy) terms for being used with the Forchheimer equation. Measurements were made using 49-mm "straight through" and 101-mm diameter "expanding flow field" designs. Results from the two designs are compared with calculations made using COMSOL $4.2 \mathrm{a}^{\circledR} 2 \mathrm{D}$ axial symmetric finite element modeling (FEM), as a function of velocity and filter PPI. Permeability results are correlated using directly measurable parameters and compared with the previously published results. Development of improved wall sealing $(49 \mathrm{~mm})$ and elimination of wall effects $(101 \mathrm{~mm})$ have led to a high level of agreement between experimental, analytic, and FEM methods ( \pm 0 to $7 \mathrm{pct}$ on predicted pressure drop) for both types of experiments. Tortuosity has been determined by two inductive methods, one using cold-solidified samples at $60 \mathrm{kHz}$ and the other using liquid metal at $50 \mathrm{~Hz}$, giving comparable results.
\end{abstract}

DOI: $10.1007 / \mathrm{s} 11663-013-9799-7$

(C) The Minerals, Metals \& Materials Society and ASM International 2013

\section{INTRODUCTION}

CERAMIC foam filters (CFFs) have been used commercially in the aluminum foundry industry for more than four decades ${ }^{[1]} \mathrm{CFFs}$ are industrially applied to remove small $(<50 \mu \mathrm{m})$ solid inclusions (e.g., oxides $-\mathrm{Al}_{2} \mathrm{O}_{3}$, spinels - $\mathrm{MgO} \cdot \mathrm{Al}_{2} \mathrm{O}_{3}$, or carbides - $\mathrm{SiC}$, $\mathrm{Al}_{4} \mathrm{C}_{3}$ ) and large oxide films, primarily for the production of premium quality aluminum products.

A research effort has been recently undertaken with the objective of using electromagnetic fields to achieve improved purification of liquid aluminum using commercial CFFs (30-80 PPI). ${ }^{[2,3]}$ It was found in the current study that the vertical gradient in the Lorentz forces

MARK WILLIAM KENNEDY, Ph.D. Candidate, is with the Department of Material Science and Engineering, Norwegian University of Science and Technology (NTNU), 7491, Trondheim, Norway and is now Chief Technology Officer, with the Proval Partners S.A., 1004, Lausanne, Switz. Contact e-mail: m.kennedy@provalp. com KEXU ZHANG, formerly Masters Student, Department of Material Science and Engineering, Norwegian University of Science and Technology (NTNU), and is now Product Engineer, with the Wartsila Norway A.S., 5420, Rubbestadneset, Norway. ROBERT FRITZSCH, Ph.D. Candidate, and JON ARNE BAKKEN, Professor Emeritus, are with the Department of Material Science and Engineering, Norwegian University of Science and Technology (NTNU). SHAHID AKHTAR, Technical Manager (Quality), is with the Wire Rod Cast House, Hydro Aluminium, Karmøy, N-4265 Håvik, Norway. RAGNHILD E. AUNE, Professor, is with the Department of Material Science and Engineering, Norwegian University of Science and Technology (NTNU) and also with the Department of Material Science and Engineering, Royal Institute of Technology (KTH), 10044, Stockholm, Sweden.

Manuscript submitted December 9, 2012.

Article published online February 9, 2013.
$(\vec{J} \times \vec{B})$ induced strong movements in the liquid metal. Based on preliminary finite element magneto-hydrodynamic (MHD) modeling and experimental observation of liquid movement within the equipment, velocities of up to $0.2 \mathrm{~m} / \mathrm{s}$ are anticipated to exist within the filter elements. This velocity is approximately one order of magnitude higher than typical casting velocity for these types of commercial filters ${ }^{[4]}$ and indicates that MHD dominates the flow field development. The modified filtration process can therefore not be understood, without first comprehending the impact of the Lorentz "driving" forces interacting with the resistance to flow produced by the permeability of the porous media, at these unusually high velocities.

The transition of pressure drop from first- to secondorder behaviors for 65 and 80 PPI CFFs using water has been reported to be in the range from 0.01 to $0.015 \mathrm{~m} / \mathrm{s}$ and to be beyond $0.015 \mathrm{~m} / \mathrm{s}$ for 40 and 50 PPI filters. ${ }^{[5]}$ In order to model MHD more accurately using finite element modeling (FEM) at high velocity of liquid, it was necessary to obtain both first-order (Darcy) and second-order (NonDarcy) terms for use with the Forchheimer equation ${ }^{[6]}$.

$$
\frac{\Delta P}{L}=\frac{\mu}{k_{1}} V_{\mathrm{s}}+\frac{\rho}{k_{2}} V_{\mathrm{s}}^{2}
$$

where $\Delta P$ is pressure drop (Pa), $L$ is the filter thickness $(\mathrm{m}), V_{\mathrm{s}}$ is the fluid superficial velocity $(\mathrm{m} / \mathrm{s}), \mu$ is the fluid dynamic viscosity $(\mathrm{Pa} \mathrm{s}), \rho$ is the fluid density $\left(\mathrm{kg} / \mathrm{m}^{3}\right)$, and $k_{1}\left(\mathrm{~m}^{2}\right)$ and $k_{2}(\mathrm{~m})$ are the empirical constants called the Darcian and non-Darcian permeability coefficients, respectively. Equation [1] represents the sum of viscous (first term) and kinetic energy losses (second term). 
Permeability experiments were therefore conducted using water with commercial alumina CFFs of 30, 40, 50, and 80 PPI. In order to understand and correlate the obtained results, it was necessary to simultaneously study the morphology of the filters including cell (pore), window and strut sizes, porosity, and tortuosity.

\section{THEORY}

Permeability is an important parameter for the characterization of CFFs, since it is required to predict the flow rate obtainable for an imposed pressure gradient (e.g., the casting rate for a given metal head and filter area) or to be able to predict the pressure drop (and therefore the required head or elevation change) necessary to achieve a specific flow rate for a fixed filter area (as in the design of a casting line and filter bowl). The correlation between flow and pressure drops can be obtained empirically by fitting experimental data as per Eq. [1] or by prediction using "easily" the measured physical properties such as porosity, $\varepsilon$ (unitless), characteristic porous media dimensions, and the known liquid properties. The Ergun equation is often applied to predict the pressure drop in beds of solids ${ }^{[7]}$.

$$
\frac{\Delta P}{L}=150 \frac{(1-\varepsilon)^{2}}{\varepsilon^{3}} \frac{\mu V_{\mathrm{s}}}{d_{\mathrm{p}}^{2}}+1.75 \frac{(1-\varepsilon) \rho V_{\mathrm{s}}^{2}}{\varepsilon^{3}} \frac{d_{\mathrm{p}}}{d_{\mathrm{p}}}
$$

where $d_{\mathrm{p}}$ is the "equivalent" spherical particle diameter (m). Even "improved" versions of Eq. [2] are known to have deviations in the range of $\pm 50 \mathrm{pct}$, relative to actual measured packed bed pressure drops. ${ }^{[8]}$
Given that a porous solid is not a packed bed and has no clearly definable particle diameter, $d_{\mathrm{p}}$, it is possible to apply the Ergun formula using alternately the diameters of the cell, $d_{\mathrm{c}}(\mathrm{m})$, window, $d_{\mathrm{w}}(\mathrm{m})$, or strut, $d_{\mathrm{s}}(\mathrm{m})$. These diameters are indicated in Figures 1 and 2(a) through (d), for the 30 through 80 PPI filters used in this study. One would expect that the estimation errors would exceed the \pm 50 pct typical of the Ergun equation, unless an appropriate "diameter" could be defined.

Ergun defined the "equivalent" particle diameter of a non-spherical solid, $d_{\mathrm{p}}$, as the diameter of the sphere having the same "outer" specific surface area per unit solid volume, $S_{\mathrm{v}}\left(\mathrm{m}^{2} / \mathrm{m}^{3}\right)$ of the actual material in question (internal porosity, and small projections or cavities were ignored $)^{[7]}$ :

$$
d_{\mathrm{p}}=\frac{6}{S_{\mathrm{v}}}
$$

In Eq. [3], the nomenclature of Ergun is maintained. Some confusion may ensue when referring to the recent literature, where $S_{\mathrm{V}}$ is sometimes used to represent the surface area of solid per unit bed volume, i.e., $S_{\mathrm{B}}$. Equation [2] can be re-written using Eq. [3] as

$$
\frac{\Delta P}{L}=\alpha \frac{S_{\mathrm{v}}^{2}(1-\varepsilon)^{2} \mu V_{\mathrm{s}}}{\varepsilon^{3}}+\beta \frac{S_{\mathrm{v}}(1-\varepsilon) \rho V_{\mathrm{s}}^{2}}{\varepsilon^{3}}
$$

where $\alpha$ and $\beta$ are unitless empirical constants found by Ergun to be approximately 4.17 and 0.292 , respectively. ${ }^{[9]}$

Richardson et al. ${ }^{[9]}$ explored the relationship between $S_{\mathrm{v}}$ and $d_{\mathrm{w}}$ for porous ceramics and suggested applying the

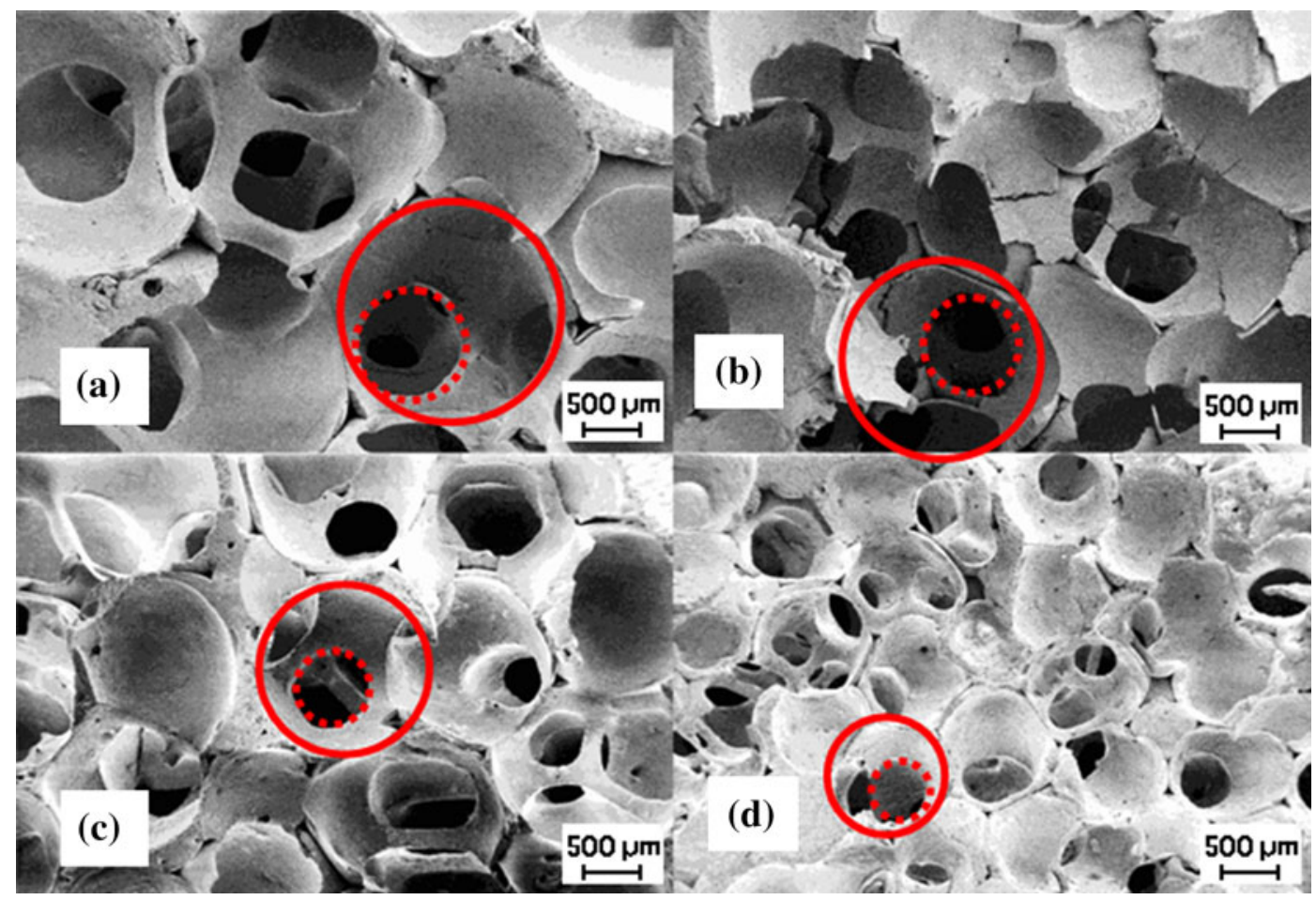

Fig. 1-Representative SEM micrographs of $30(a), 40(b), 50(c)$, and $80(d)$ PPI commercial alumina ceramic foam filters. Cell or pore sizes $\left(d_{\mathrm{c}}\right)$ are indicated by solid circles and window sizes $\left(d_{\mathrm{w}}\right)$ are indicated by dotted circles. 
hydraulic diameter, $d_{\mathrm{h}}(\mathrm{m})$, concept. They equated the hydraulic diameter to the measured window diameter:

$$
d_{\mathrm{w}}=d_{\mathrm{h}}=4 \frac{\text { wetted area }}{\text { wetted perimeter }}
$$

Assuming idealized regular pores, i.e., all with the same hydraulic diameter, a simple geometric analysis yields

$$
S_{\mathrm{v}}=\frac{4 \varepsilon}{d_{\mathrm{w}}(1-\varepsilon)}
$$

Substituting Eq. [6] into Eq. [4] yields

$$
\frac{\Delta P}{L}=66.7 \frac{\mu V_{\mathrm{s}}}{\varepsilon d_{\mathrm{w}}^{2}}+1.17 \frac{\rho V_{\mathrm{s}}^{2}}{\varepsilon^{2} d_{\mathrm{w}}}
$$

Recently, Dietrich et al.$^{[10,11]}$ proposed the following equation after correlating 2500 separate experimental values from 20 authors:
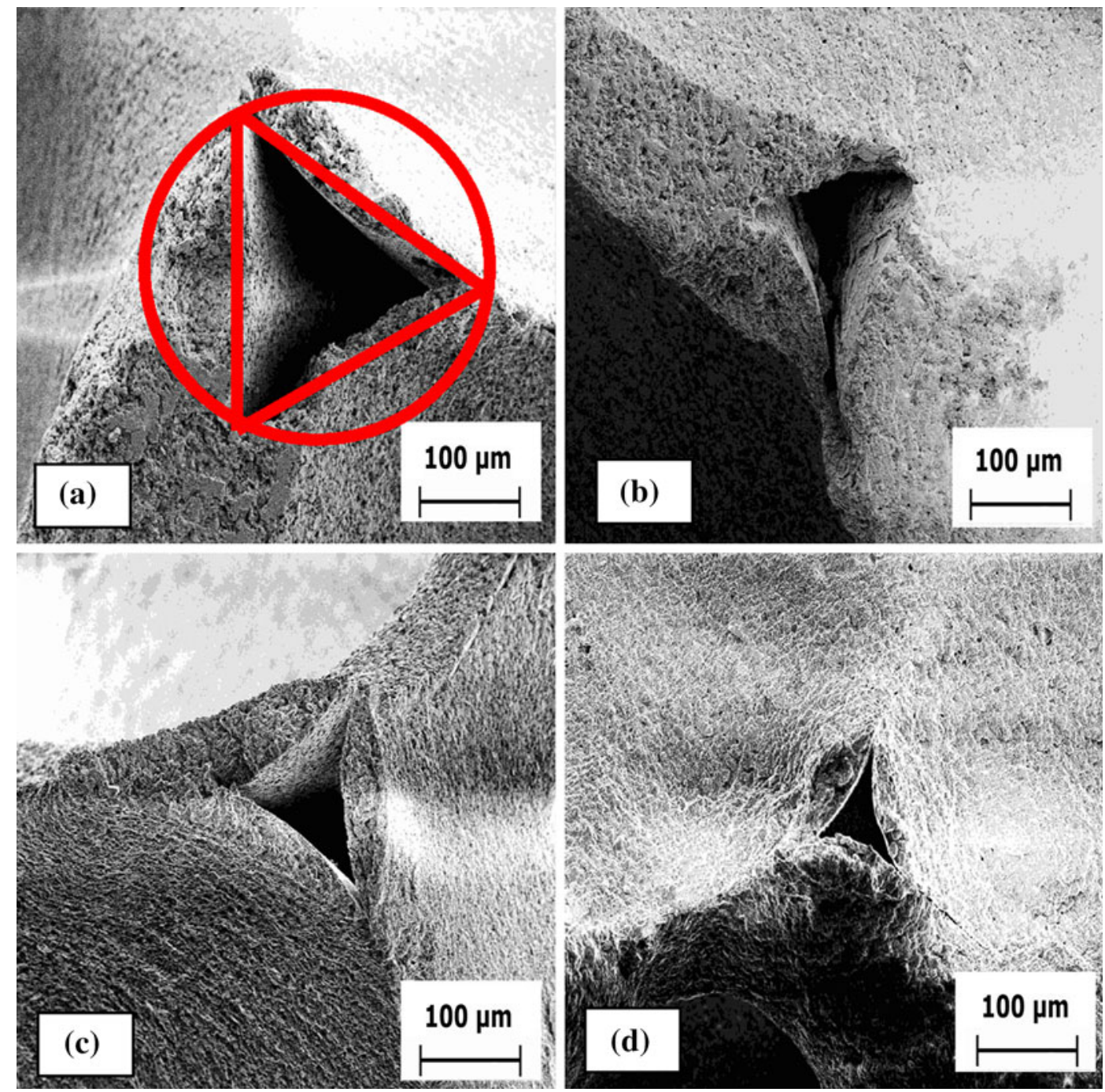

Fig. 2-Representative SEM micrographs of $30(a), 40(b), 50(c)$, and $80(d)$ PPI commercial alumina ceramic foam filters. Cell strut diameter

$\left(d_{\mathrm{s}}\right)$ is indicated for the 30 PPI filter as the solid circle. The internal porosity left by the removal of the substrate is indicated as a triangle.

The similarity between Eqs. [7] and [8] is obvious. If the hydraulic diameter is assumed equal to the window diameter in Eq. [8], then Eq. [8] will yield 40 through 50 pct higher pressure drops than Eq. [7]. ${ }^{[10]}$ As both empirical constants in Eq. [8] are larger than those in Eq. [7], it will yield higher estimated pressure drops for any velocity. Equation [8] has recently been independently shown to give excellent results using the optically determined hydraulic diameter, i.e., the equivalent circular window diameter, $d_{\mathrm{w}}{ }^{[12]}$

It should be noted that the total, $\varepsilon$, and open porosity, $\varepsilon_{\mathrm{o}}$, are of very similar magnitudes, as shown in Figure 3 for an electromagnetically primed ${ }^{[13]} 50$ PPI filter filled with an A356 aluminum alloy. Some small areas of closed porosity are shown in dotted circles as typical examples of closed porosity created by the substrate used in the filter fabrication process. Grosse et al. have described the morphological characterization of CFFs

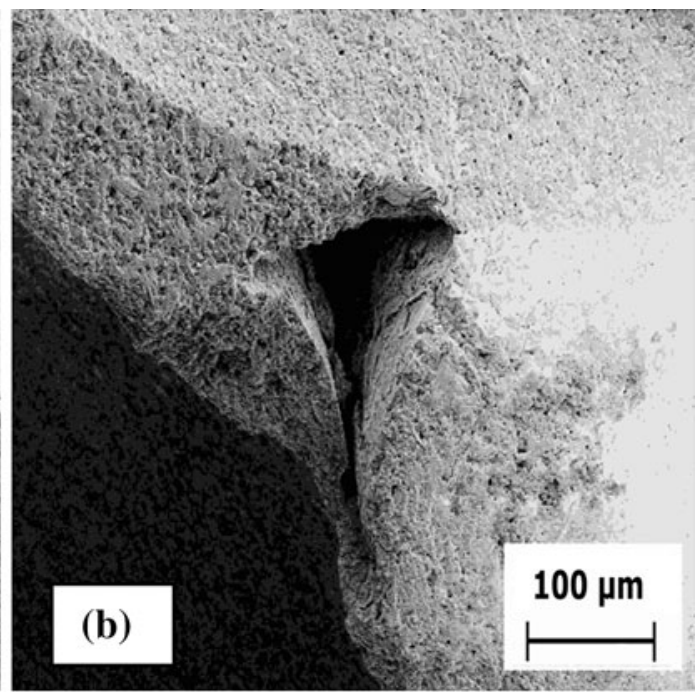


in detail, including the steps required to correctly determine total and open porosity (e.g., using mercury at up to 4000 bar). ${ }^{[1,15]}$ Grosse et al. found that the difference between the total and the open porosity is $<5$ pct of the measured value. The convention of Dietrich, i.e., equality between the total and open porosities has therefore been followed in the current study.

Total porosity, $\varepsilon$, can be determined using the true particle density, $\rho_{\mathrm{p}}\left(\mathrm{kg} / \mathrm{m}^{3}\right)$, found using pycnometry and the measured filter mass, $m_{\mathrm{f}}(\mathrm{kg})$ for a known filter volume $V_{\mathrm{f}}\left(\mathrm{m}^{3}\right)$, i.e., the filter density, $\rho_{\mathrm{f}}\left(\mathrm{kg} / \mathrm{m}^{3}\right)$ :

$$
\varepsilon=1-\frac{m_{\mathrm{f}}}{\rho_{\mathrm{p}} V_{\mathrm{f}}}=1-\frac{\rho_{\mathrm{f}}}{\rho_{\mathrm{p}}}
$$

Tortuosity, $\tau$ (unitless), is here defined as the ratio between the actual length traversed by the liquid flow, $L_{\mathrm{a}}(\mathrm{m})$, and the linear thickness of the filter, $L(\mathrm{~m})$ :

$$
\tau=\frac{L_{\mathrm{a}}}{L}
$$

Tortuosity can be determined by electromagnetic induction experiments using alloys of known electrical conductivity, $\sigma_{\mathrm{m}}\left(\Omega^{-1} \mathrm{~m}^{-1}\right)$. The actual resistance of a filter element filled with metal, as shown in Figure 3, can be compared with the known resistance of an equivalent path length of metal either liquid or solid and the tortuosity determined. The conductivity is related to the path length, area, and resistance by

$$
\sigma_{\mathrm{m}}=\frac{l}{a R_{\mathrm{m}}}
$$

where $\sigma_{\mathrm{m}}$ is the conductivity of the metal $\left(\Omega^{-1} \mathrm{~m}^{-1}\right)$ at the measurement temperature, $l$ is the length of the conducting path $(\mathrm{m}), a$ is the area of the conducting path $\left(\mathrm{m}^{2}\right)$, and $R_{\mathrm{m}}$ is the resistance of the metal along the conducting path $(\Omega)$.

Within the filter, the available conducting area is reduced by the presence of non-conducting obstructions (e.g., trapped gas or solid and filter media), and the conducting path length is increased because of the tortuosity. Assuming that the filter media is the only significant obstruction, the reduced apparent electrical conductivity can be estimated as follows:

$$
\sigma_{\mathrm{f}}=\frac{\sigma_{\mathrm{m}} \varepsilon}{\tau}
$$

where $\sigma_{\mathrm{f}}$ is the apparent electrical conductivity of the metal-impregnated filter $\left(\Omega^{-1} \mathrm{~m}^{-1}\right)$.

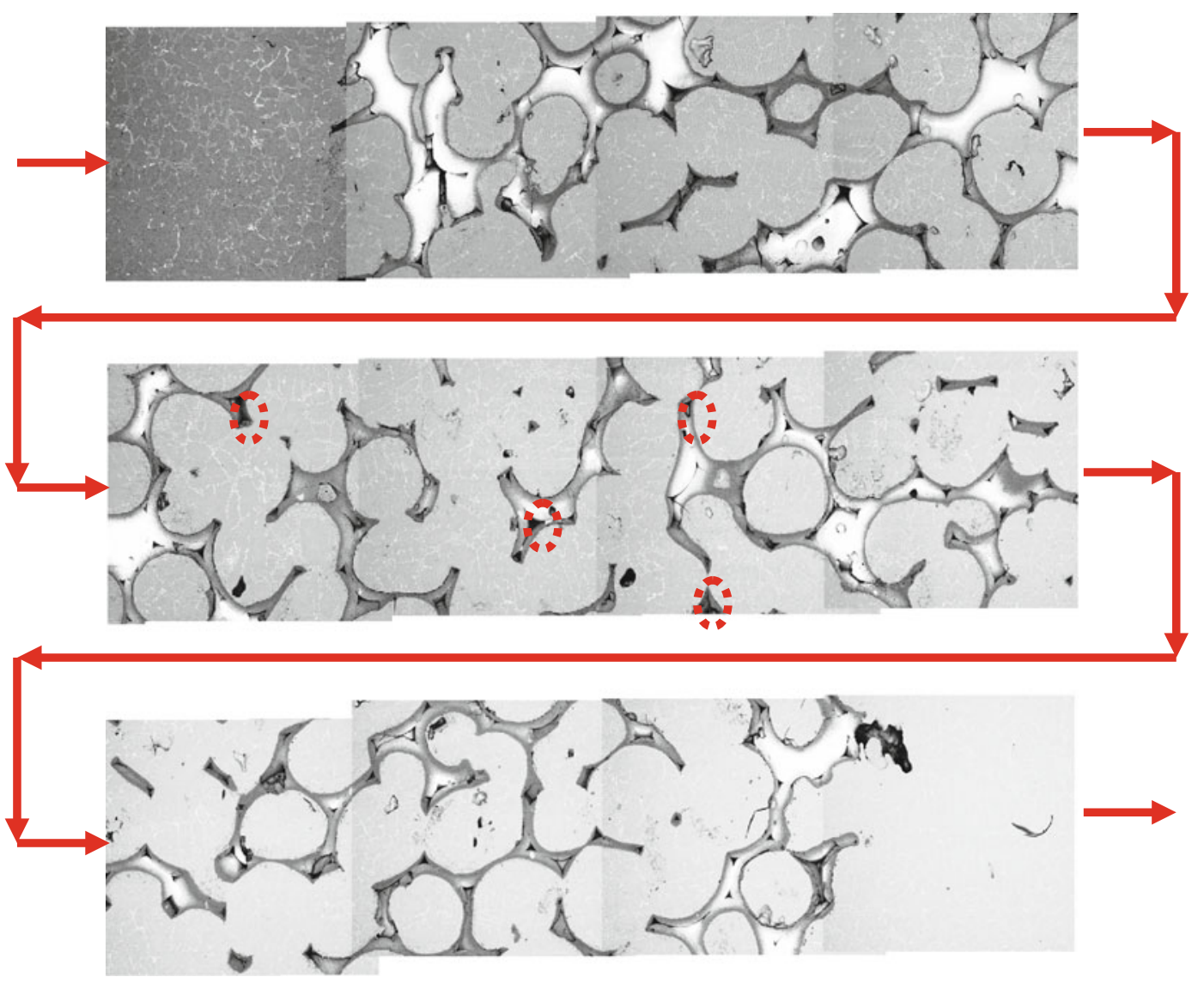

Fig. 3-Representative SEM micrographs showing a full 50-mm thickness vertical profile through a well-primed 50 PPI commercial alumina ceramic foam filter. Areas of "closed" porosity can be seen in black, some of which are highlighted by dotted circles as examples. Visual inspection confirms that nearly the entire porosity is filled with metal, i.e., substantive agreement between total, $\varepsilon$ and open porosity, $\varepsilon_{\mathrm{o}}$. 
Rearranging Eq. [12] to solve for the tortuosity yields

$$
\tau=\varepsilon \frac{\sigma_{\mathrm{m}}}{\sigma_{\mathrm{f}}}
$$

\section{EXPERIMENTAL}

\section{A. Filter Characterization}

Commercial filters of $30,40,50$, and 80 PPI where examined by a combination of light microscopy, optical scanning, and scanning electron microscope (SEM) to determine cell, $d_{\mathrm{c}}$, window, $d_{\mathrm{w}}$ and strut, $d_{\mathrm{s}}$ dimensions. 200 counts were made for each cell and window determination, on the original, uncut surface of the 50mm-thick alumina CFFs. 40 counts were made of the strut dimensions, which were measured at their thinnest point.

Porosities of the 101-mm filter sections used in these experiments were determined using Eq. [9] by precise measurement of the filter dimensions, calculation of the total volume, and weighing on an analytic balance. Overall precision was estimated to be \pm 0.2 pct porosity. The 49-mm-diameter filters used during testing were cut from the center of the 101-mm filters, and the porosities were assumed as constant. For the 30, 50, and 80 PPI filters, porosity measurements were also taken for all the commercially sized filter elements for comparison (23", $20^{\prime \prime}$, and $23^{\prime \prime}$ square).

The electrical conductivity of the solid aluminum and sectioned metal-impregnated filter elements were measured using an AutoSigma 3000 inductive conductivity analyzer (General Electric Inspection Technologies, UK) to an accuracy of \pm 0.5 pct using a $12.7-\mathrm{mm}$ diameter 47P001 probe. The instrument was calibrated before use against certified aluminum standards of 8.64 and 60.37 pet IACS (International Annealed Copper Standard). For reference: 100 pct IACS conductivity is $58.0 \mathrm{MS} / \mathrm{m},{ }^{[16]}$ and typical electrical grade aluminum (i.e., "commercially" pure) has a nominal conductivity of $\sim 61$ pct IACS. Measurements were taken on metal frozen over and under the filter elements, and on both vertical and horizontal cuts through the filters. A frequency of $60 \mathrm{kHz}$ was used, which resulted in electromagnetic penetration depths from $\sim 0.3$ to $0.5 \mathrm{~mm}$, depending on the alloy's conductivity and filter's tortuosity. An arithmetic average on 20 through 30 readings was used to estimate the room temperature conductivity of the metal-impregnated filter. Circular induced currents (i.e., eddy currents) were generated by the probe, and these represent current flow in either the $\mathrm{r}-$ phi axes (horizontal cut) or the $\mathrm{r}-\mathrm{Z}$ axes (vertical cut). It was therefore expected that readings could be different, if any anisotropy existed in the filter morphology.

The effective electrical conductivities of the filters were also determined from liquid metal electromagnetic induction experiments, using procedures described in detail elsewhere. ${ }^{[2,3,17]}$ A schematic of the apparatus used is shown in Figure 4(a), and a photograph is shown in Figure 4(b). The power induced in a tight stack of three 50-mm-thick, and $~ 100$-mm-diameter filters of 30 , 40,50 , or 80 PPI was determined electrically at a known temperature (and therefore metal electrical conductivity), while being filled with "commercially pure" aluminum alloys with initial electrical conductivity from 61 to 62 pct IACS. Temperatures were logged every $100 \mathrm{~ms}$ by type $\mathrm{K}$ thermocouples located under and over the 150 -mm stack of filters.

An average temperature was used to estimate the liquid metal conductivity within the filter elements, starting with the literature conductivity data for ultra pure metal, and correcting for the actual measured room temperature conductivity of the clean metal after experimentation ${ }^{[18]}$ :

$$
\sigma_{\mathrm{m}}=\frac{I A C S_{\mathrm{m}}^{293 \mathrm{~K}}}{24.77 \times 10^{-8}\left(1+0.000571\left[T_{\mathrm{m}}-933.2\right]\right) 65}
$$

where IACS $_{\mathrm{m}}^{293 \mathrm{~K}}$ is the average room temperature conductivity of the solidified metal used during the experiment (pct IACS), and $T_{\mathrm{m}}$ is the temperature of the liquid alloy under experimental conditions $(\mathrm{K})$.

A $50-\mathrm{Hz}$ electromagnetic field was applied along the long $(z)$ axis of the stack of filters. This time-varying magnetic field induced circular currents along the phiaxis, through the metal-impregnated interstitial spaces of the filter elements. The induced power was determined electrically, using high accuracy instrumentation measuring changes in coil power. Power measurements were taken using a Fluke 43B power analyzer (Fluke, USA), with a resolution of $100 \mathrm{~W}$. Coil current measurements were made with an i1000S inductive current probe (Fluke, USA), with an accuracy of \pm 1 pct and a resolution of $1 \mathrm{~A}$.

The effective electrical conductivity of the filter elements where then determined from the equipment geometry, the experimentally measured power (W), and the applied coil current (A), with 2D axial symmetric FEM modeling, using the commercial COMSOL $4.2 \mathrm{a}^{\circledR}$ software. Details of the validation of the modeling methods can be found elsewhere. ${ }^{[19,20]}$ The FEM model had been previously shown to have $\sim \pm 2$ pct uncertainty in power estimation, compared with direct calorific measurements taken in solid billet heating experiments. ${ }^{[20]}$ The effective conductivity was determined by adjusting the model conductivity, until the model's induced power precisely matched the measured induced power, for the given applied current. The tortuosity along the phi-axis could then be determined using Eq. [13].

The uncertainty in the tortuosity estimates then represents the sum of the uncertainty in the model ( \pm 2 pct), measured workpiece power $(\sim \pm 10$ pct), and any error in the solid ( \pm 0.5 pct) and liquid $( \pm 5$ to $10 \mathrm{pct}$ ) estimates of the metal conductivity. Variation of up to \pm 20 pct should therefore be expected on a single reading of tortuosity. Five through eight individual power readings taken once every minute were averaged to produce 1 power/tortuosity measurement. Three through eight sets of measurements (depending on the degree of thermal and electrical stability) were then 


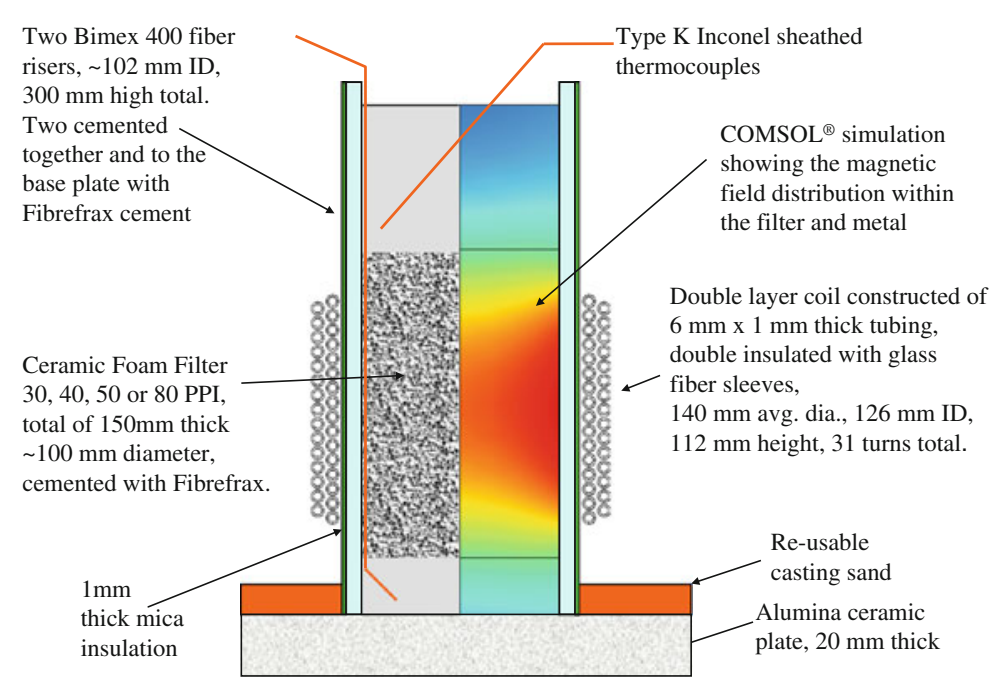

(a)

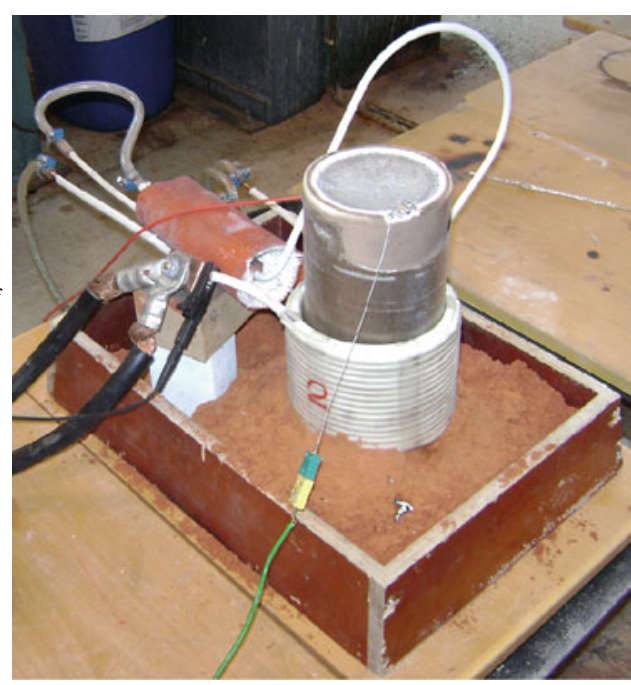

(b)

Fig. 4-Schematic of the filter tortuosity apparatus (a) and photograph (b), showing a two-layer, 31-turn (total) induction coil, operated from 371 to $734 \mathrm{~A}$, using line frequency $50-\mathrm{Hz}$ AC power.

individually modeled using FEM and averaged to produce the final estimate of tortuosity for each filter type.

The resulting tortuosity measurements are representative of the entire cross section of the filter, as the electromagnetic penetration depth exceeded the filter radius $(50 \mathrm{~mm})$, because of the low electrical conductivity of the molten metal $(\sim 10$ pct of the room temperature solid metal electrical conductivity), combined with the low frequency of operation $(50 \mathrm{~Hz})$.

\section{B. Liquid Permeability: Experimental Conditions and Procedures}

The liquid permeability of 50 -mm-thick commercial ceramic foam filters (CFFs) with 30, 40, 50, and 80 PPI were measured using water as the working fluid, in a temperature range from $278 \mathrm{~K}$ to $281 \mathrm{~K}\left(5^{\circ} \mathrm{C}\right.$ to $\left.8{ }^{\circ} \mathrm{C}\right)$ (typical $\rho_{\mathrm{w}}=999.9 \mathrm{~kg} / \mathrm{m}^{3}$, and $\mu_{\mathrm{w}}=1.377510^{-3} \mathrm{~Pa} \mathrm{~s}$ ). Mass flows from about 0.05 to $2 \mathrm{~kg} / \mathrm{s}$ of water were circulated through 46.4-mm ID smooth plastic piping, representing Reynolds numbers from $\sim 1200$ to 39000 and moving from laminar flow, into transitional and partially turbulent pipe flow in the inlet pipe. ${ }^{[21]}$

Eight through ten different experimental velocities were used to measure pressure drop for each filter. 101$\mathrm{mm}$ nominal diameter elements were cut from the full size $\left(20^{\prime \prime}\right.$ or $23^{\prime \prime}$ square) commercial filters using diamond bores. The 49-mm diameter filter elements were cut from the center of the 101-mm filter elements. The true diameter and thickness of each filter element were measured using a micrometer, and the averages of six readings were used in the subsequent experimental analysis.

The main Plexiglas filter apparatus used in the permeability experiments is shown in Figures 5(a) and (b). The use of a transparent housing ensured that all air was completely eliminated from the system before recording any pressure readings. Two apparatus designs where used: one for the 101-mm diameter filters, shown in Figure 5(a); and the second, for 49-mm filters, shown in Figure 5(b). The sealing arrangements were of critical importance in the design of the filter housings. In order to prevent wall effects from significantly affecting the results, it is of paramount importance to prevent the flow from bypassing the filter and moving along the walls. Therefore, in the final experimental procedure, high-viscosity silicone grease was used to smoothen the outer surface of each filter (fill the outer-most broken or cut cells), which were then wrapped in paper and pressed tightly into the holder. Upon making contact with water, swelling of the cellulose fibers provided a seal of negligible permeability. It is necessary to seal the entire side surface of the filter, as normal O-rings are unable to stop the flow from bypassing along the wall.

In the 101-mm diameter design, the impacts of "wall effects" are essentially eliminated by allowing the flow field to expand within the filter element and making the outer wall a "stagnant" region. FEM is then required to elucidate the flow field and calculate an "effective" flow diameter for use with Eq. [1], which assumes a single representative diameter. It was necessary to use soft rubber gasket materials to press into the top and bottom faces of the filter elements, to prevent horizontal flow at the inlet or outlet and provide a clearly defined "entrance/exit diameter" of $49 \mathrm{~mm}$ for later CFD analysis.

The pressure transducer used was a DF-2 (AEP Transducers, Italy), with measuring range from 0 to 1 bar, and equipped with an output range from 4 to $20 \mathrm{~mA}$. The transducer was factory calibrated and certified to an error of $< \pm 0.04$ pct of reading, over the full scale from 0 to 1 bar, using a six-point calibration. During the experiments, the current produced by the transducer at zero liquid flow velocity was determined 
manually using a FLUKE 26 III, True RMS Multimeter (Fluke, USA) to a precision of $0.001 \mathrm{~mA}(6.25 \mathrm{~Pa})$, using the lowest available current scale. Currents during the flow measuring periods were computer data logged at $100-\mathrm{mS}$ intervals by conversion to signal range from 0 to $5 \mathrm{~V}$, with a resolution of $0.001 \mathrm{~V}$ or $0.004 \mathrm{~mA}$ (i.e., $25 \mathrm{~Pa}$ resolution). At greater than $4.1 \mathrm{~mA}$, no bias could be detected between the manual and automated current readings, at the available $0.01 \mathrm{~mA}$ resolution (the FLUKE meter switched to a lower resolution at greater than $4.099 \mathrm{~mA})$. The length between the pressure taps was $160 \mathrm{~mm}$ (varying $\sim \pm 1 \mathrm{~mm}$ ). One tap was located at $1.5 \mathrm{~L} / \mathrm{Ds}$ up-stream and the other $0.75 \mathrm{~L} / \mathrm{Ds}$ downstream of the filter element.

The required inlet lengths to fully develop the flow regime are

Laminar $^{[22]}$

$$
\frac{L_{\text {inlet }}}{d_{\text {pipe }}} \approx 0.03 R e_{\text {pipe }}
$$

Turbulent ${ }^{[23]}$ :

$$
\frac{L_{\text {inlet }}}{d_{\text {pipe }}} \approx 4.4 R e_{\text {pipe }}^{1 / 6}
$$

where $L_{\text {inlet }}$ is the required inlet length $(\mathrm{m})$ to fully develop the flow profile (e.g., 99 pct centerline approach), $d_{\text {pipe }}$ is the inside diameter of the pipe $(\mathrm{m})$, and $R e_{\text {pipe }}$ is the pipe Reynolds number (unitless).

The filter holders were used in a piping circuit containing ten $90 \mathrm{deg}$ bends, with five being located before and five after the filter holder apparatus. There was a total of $8.3 \mathrm{~m}$ of piping in the standard "short" inlet configuration and $12.3 \mathrm{~m}$ in the "long" inlet configuration. In the "short" configuration, there were $22 \mathrm{~L} / \mathrm{Ds}$ of straight sections of pipe before the filter housing, and in the "long" configuration, there were $65 \mathrm{~L} / \mathrm{Ds}$.

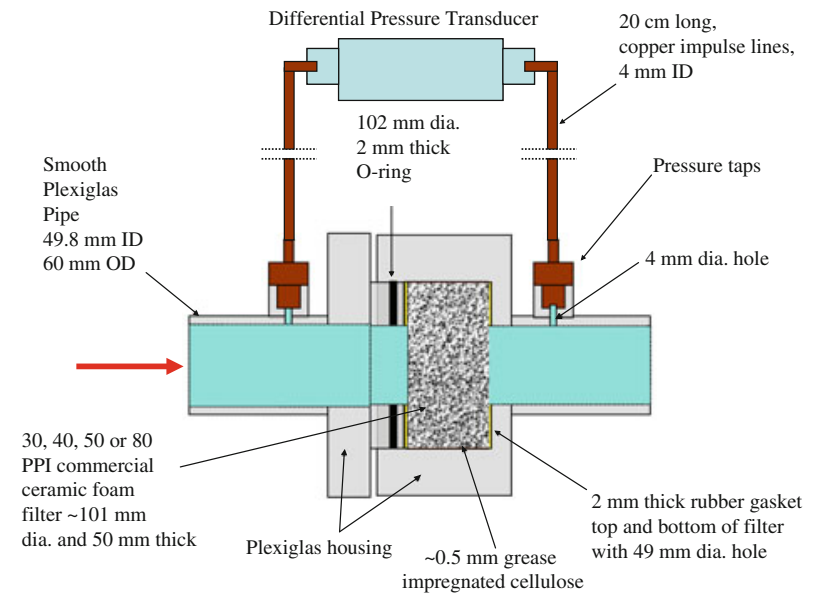

(a)
From Table I, it can be seen that except at very low or very high velocity, the "short" inlet should be adequate to achieve fully developed flow (i.e., "99 pct approach"), while the "long" inlet should be adequate at all Reynolds numbers. The impact of back-to-back and out-of-phase $90^{\circ}$ bends on the flow will be to promote turbulence even at low Reynolds numbers. Owing to the difficulty of simulating such a complex flow path (originating at a centrifugal pump), 3D fluid flow modeling was not deemed to be warranted. Various biased flow inlet conditions were tested for the "long" and "short" inlet lengths using 2D axial symmetry FEM and were found to have only second-order effects at the most. For FEM modeling, an extremely simplistic uniform inlet velocity was therefore assumed at the entrance to the pressure apparatus shown in Figures 5(a) and (b); the reasonableness of this assumption then is subject to empirical verification.

The pressure in the system was produced by a $1000 \mathrm{~W}$, 0.8 bar maximum submersible pump, which was located at the bottom of a 70-cm-tall holding tank of $100-\mathrm{L}$ capacity. The water flow rate was regulated using a DN 25 ball valve, located immediately at the outlet of the

Table I. Required Inlet Length to Fully Develop Flow as a

\begin{tabular}{|c|c|c|c|c|}
\hline $\begin{array}{l}\text { Velocity } \\
(\mathrm{m} / \mathrm{s})\end{array}$ & Pipe $R e$ & $\begin{array}{l}\text { L/D Inlet } \\
\text { Laminar }\end{array}$ & $\begin{array}{l}\text { L/D Inlet } \\
\text { Turbulent }\end{array}$ & $\begin{array}{c}\text { Estimated L/D } \\
\text { Inlet }\end{array}$ \\
\hline 0.03 & 1010 & 30.3 & $\mathrm{~N} / \mathrm{A}$ & 30.3 \\
\hline 0.05 & 1684 & 50.5 & 15.2 & 32.8 \\
\hline 0.1 & 3368 & $\mathrm{~N} / \mathrm{A}$ & 17.0 & 17.0 \\
\hline 0.2 & 6736 & $\mathrm{~N} / \mathrm{A}$ & 19.1 & 19.1 \\
\hline 0.4 & 13472 & $\mathrm{~N} / \mathrm{A}$ & 21.5 & 21.5 \\
\hline 0.8 & 26945 & $\mathrm{~N} / \mathrm{A}$ & 24.1 & 24.1 \\
\hline 1 & 33681 & $\mathrm{~N} / \mathrm{A}$ & 25.0 & 25.0 \\
\hline 1.2 & 40417 & $\mathrm{~N} / \mathrm{A}$ & 25.8 & 25.8 \\
\hline
\end{tabular}
Function of Pipe Reynolds Number

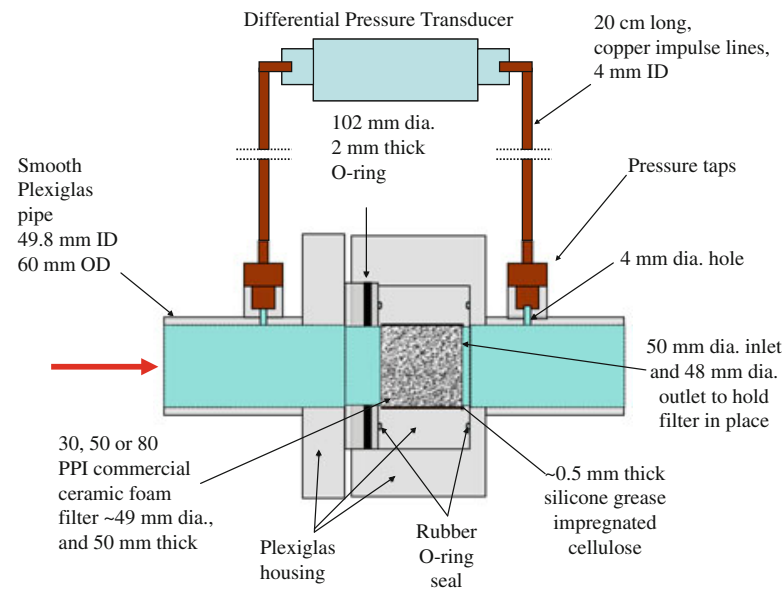

(b)

Fig. 5-Apparatus used for the 101-mm (a) and the 49-mm (b) diameters, 50-mm-thick filter experiments, both drawn approximately to scale. Fluid flow was from right to left. 
pump. The flow rate was determined by accumulating mass over the measuring period in a second 100-L tank, located on a digital balance, equipped with an output range from 4 to $20 \mathrm{~mA}$. The scale had a resolution of $10 \mathrm{~g}$ and a maximum reading of $100 \mathrm{~kg}$. The zero and span of the scale were verified for accuracy at the 10 -g resolution using test weights to 50 pct of full scale before use. The rate of mass gain of the measuring tank was computer data logged at $100 \mathrm{~ms}$ intervals. Depending on the required mass flow, from 10 to $50 \mathrm{~kg}$ of water was accumulated. "Sloshing" of the water in the tank (mainly at very high flows) produced noise on the weight signal that was smoothened by taking a 1-s rolling average (rolling average of 10 readings), which resulted in a maximum flow rate uncertainty of $\sim \pm 0.5$ pct of reading. The flow rate was found from the slope of the accumulation of mass with time and determined using least squares regression over the whole measuring period (typical $R^{2}=0.9985$ ). Temperatures were measured using a 1-mm-diameter Inconel-sheathed Type $\mathrm{K}$ thermocouple located in the holding tank, and the temperature data were also computer logged.

Eq. [1] was used with the measured pressure gradients and superficial velocities to determine the Forchheimer terms $k_{1}$ and $k_{2}$. Each estimate used the appropriate water temperature, and therefore density and viscosity, representative of the individual mass flow reading. Superficial velocity was determined using the actual measured filter diameter for the 49-mm filter elements or using the "effective" flow field diameter for the 101-mm filter elements (to be described in more detail later). Final $k_{1}$ and $k_{2}$ values are the arithmetic average of the 8 through 10 values determined for each filter element.

\section{RESULTS}

\section{A. Filter Characterization}

SEM micrographs indicating the physical structures ranging from 30 to 80 PPI alumina ceramic foam filters used in this study are shown in Figures 1 and 2. The filter porosity and key dimensions are summarized in Table II. Sample porosity was calculated using Eq. [9] from the measured particle density of $3.48 \pm 0.02 \mathrm{~g} / \mathrm{cm}^{3}$ (average of 3 readings). Overall filter porosity indicated in Table II is the average result of 2 through 4 readings on industrial $20^{\prime \prime}$ or $23^{\prime \prime}$ filters.

Histograms have been made of the 200 counts of window diameter, $d_{\mathrm{w}}$ as can be seen in Figures 6(a) through (d) for the 30 to 80 PPI filter types. Median values are indicated by dotted lines. Average cell diameter, $d_{\mathrm{c}}$, has been plotted $v s$. the average window diameter, $d_{\mathrm{w}}$ in Figure 7 , and the results correlated according to the following equation:

$$
d_{\mathrm{c}}=1.79 d_{\mathrm{w}}, R^{2}=0.988
$$

The linear relationship between cell and window diameters implies a simple geometric relationship, likely originating with the original substrate used during the filter fabrication process. There is an excellent agreement between the current findings and the literature values for both cell and window sizes for similar alumina CFFs. ${ }^{[24]}$

\section{B. Filter Tortuosity Measurements}

Filter tortuosity has been determined for metalimpregnated 30, 40, 50, and 80 PPI filters. Measurements have been obtained with the metal in both liquid and solid states. The metal used was "commercially" pure electrical grade aluminum, which was determined to have $61.7 \pm 0.1$ pct IACS conductivity (average of 10 readings) before melting. After melting, the solidified metal samples were found to have conductivities of 59.7 pct (30 PPI), 54.0 pct (40 PPI), 60.0 pct (50 PPI), and 61.0 pct (80 PPI). The hot metal experiments were conducted using the apparatus already shown in Figure 4, and detailed results can be found in Appendix Table I.

Hot liquid metal (FEM estimate) and cold-solidified filter section measurements (average, vertical, and horizontal cuts) and calculated tortuosity results (using the hot metal data) are summarized in Table III, for all four filter types. Experimental data have also been plotted in Figure 8.

Results show reasonable agreement between hot and average cold conductivity ratios, given the different equipments, temperatures, and frequencies involved in these two sets of measurements. The conductivity ratio between the metal and metal-impregnated filters for the liquid metal experiments was correlated according to the following equation:

$$
\frac{\sigma_{\mathrm{m}}}{\sigma_{\mathrm{f}}}=5.10-3.8 \times 10^{3} d_{\mathrm{w}}, R^{2}=0.981
$$

The variation in conductivity ratios between the horizontal or vertical cuts appeared to be random in nature. The observed variations may be the result of the

Table II. Summary of Basic Filter Physical Properties

\begin{tabular}{lccccc}
\hline $\begin{array}{l}\text { Filter } \\
\text { Type (PPI) }\end{array}$ & $\begin{array}{c}\text { Filter Porosity } \\
\text { (Eq. [9]) }\end{array}$ & $\begin{array}{c}\text { Full Filter } \\
\text { Porosity (Eq. [9]) }\end{array}$ & $\begin{array}{c}\text { Cell Diameter, } \\
d_{\mathrm{c}}(\mu \mathrm{m})\end{array}$ & $\begin{array}{c}\text { Window Diameter, } \\
d_{\mathrm{w}}(\mu \mathrm{m})\end{array}$ & $\begin{array}{c}\text { Strut Diameter, } \\
d_{\mathrm{s}}(\mu \mathrm{m})\end{array}$ \\
\hline 30 & 0.892 & $0.890 \pm 0.0002$ & $1668 \pm 417$ & $961 \pm 190$ & $185 \pm 41$ \\
40 & 0.900 & N/A & $1306 \pm 251$ & $698 \pm 151$ & $211 \pm 46$ \\
50 & 0.863 & $0.864 \pm 0.004$ & $1132 \pm 130$ & $623 \pm 120$ & $190 \pm 36$ \\
80 & 0.865 & $0.860 \pm 0.004$ & $683 \pm 87$ & $383 \pm 87$ & $119 \pm 20$ \\
\hline
\end{tabular}

One standard deviation is indicated by the ranges. 


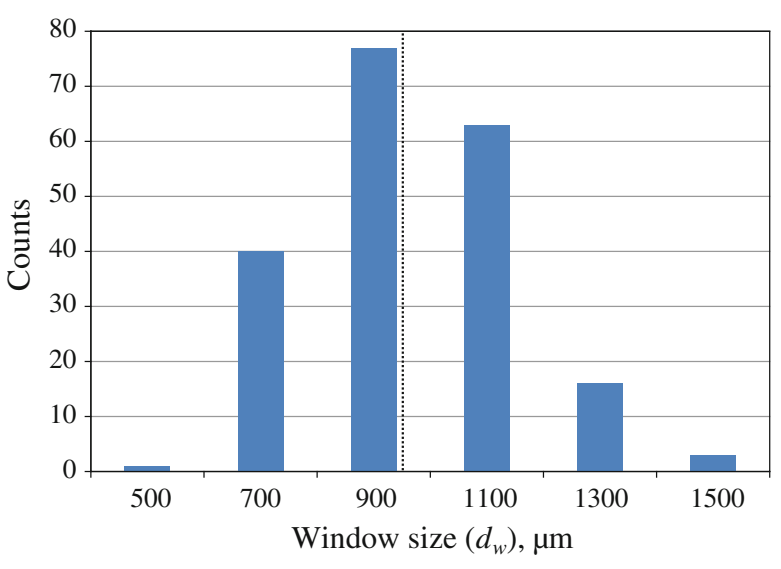

(a)

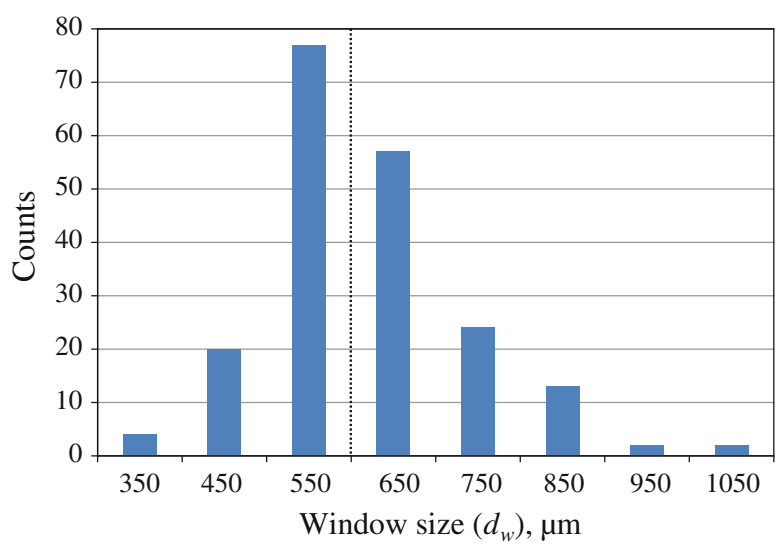

(c)

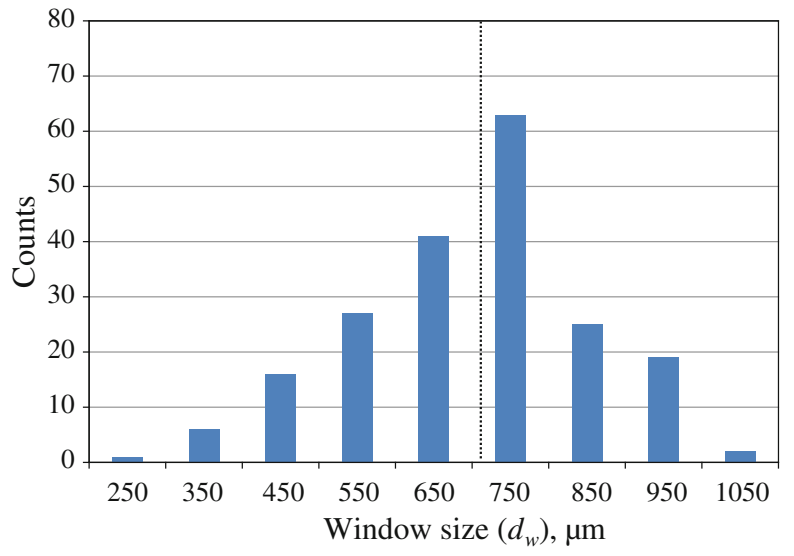

(b)

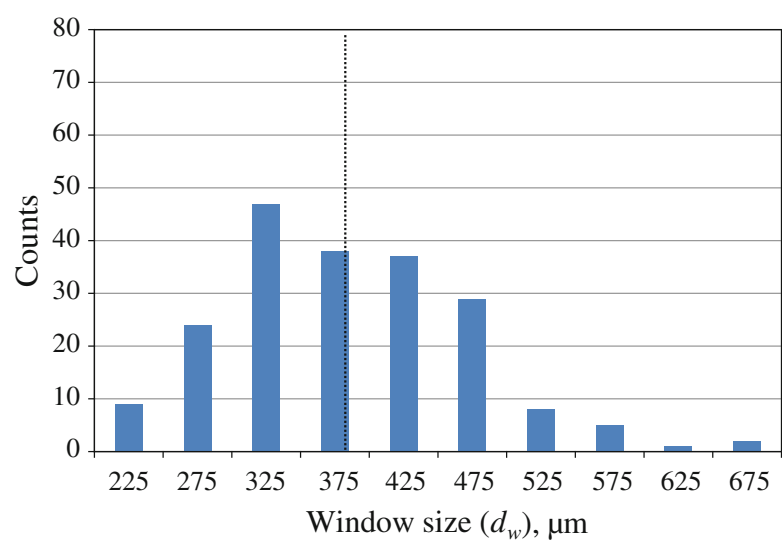

(d)

Fig. 6- Histograms of (a) 30, (b) 40, (c) 50, and (d) 80 PPI window sizes, $d_{\mathrm{w}}(\mu \mathrm{m})$. Median values are marked with dotted lines.

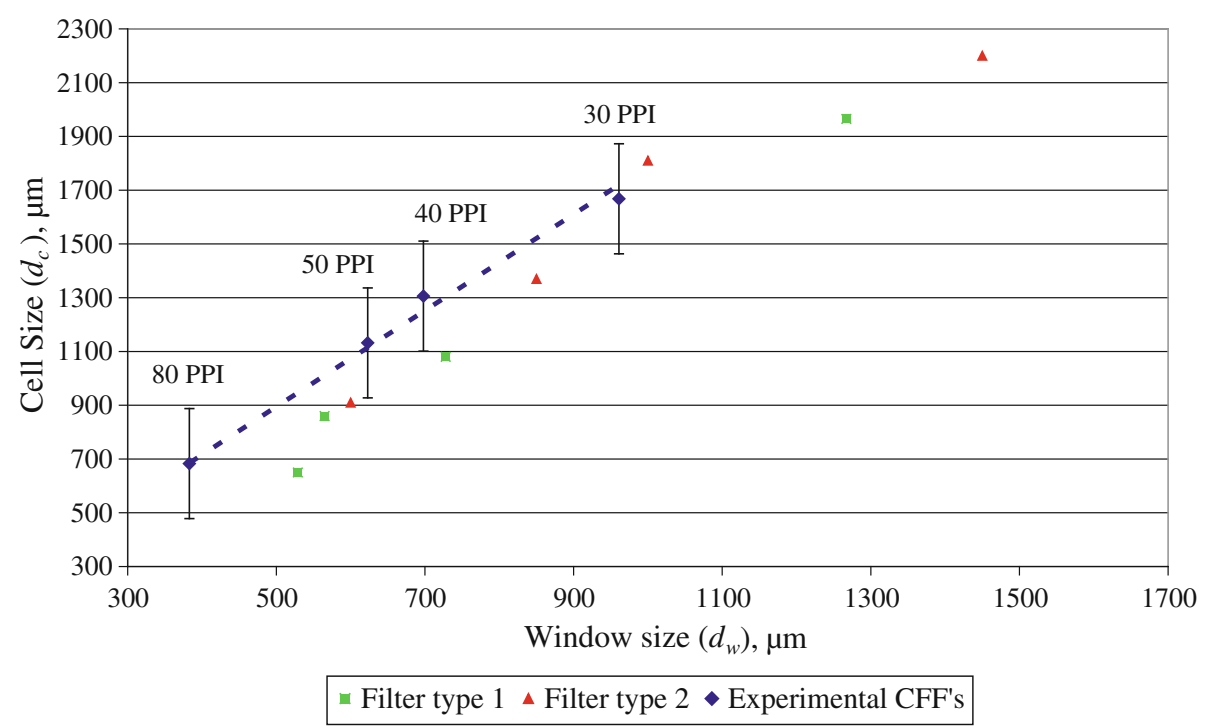

Fig. 7-Commercial ceramic foam filter cell size, $d_{\mathrm{c}} v s$. window size, $d_{\mathrm{w}}(\mu \mathrm{m})$, and comparison with the literature data. ${ }^{[24]}$ One "standard error" is indicated by the error bars.

random location of the sections through the pore structure of the filter elements and the low electromagnetic penetration depth of the high-frequency cold method, which is less than one cell diameter.
Relatively very few measured values have been published previously for ceramic foam tortuosities. Moreia et al. measured tortuosity values using an ionic conduction method equivalent to the induction method 
described here. Their values for ceramic foams of 8,20 , and 45 PPI were $1.68,1.71$, and 1.84 , respectively. ${ }^{[25]}$ Diedericks et al. have theoretically studied tortuosity in some detail, proposing a value of $\sim 1.45$ at $\varepsilon=0.88$, for "foam-like" materials. ${ }^{[26]}$ Methods, using water and ionic solutes, will likely underestimate the true filter tortuosity, because of penetration of the water and ions into the micro and nano-porosity of the filter structure itself. Liquid metal

Table III. Summary of Key Tortuosity Experimental Results

\begin{tabular}{lcccccc}
\hline $\begin{array}{l}\text { Filter } \\
\text { Type }(\text { PPI })\end{array}$ & $\begin{array}{c}\text { Filter Porosity } \\
(\text { Eq. [9]) }\end{array}$ & $\begin{array}{c}\text { Filter Tortuosity } \\
(\text { Eq. [13]) }\end{array}$ & $\begin{array}{c}\text { FEM Estimate of } \\
\text { Conductivity } \\
\text { Ratio }\left(\sigma_{\mathrm{m}} / \sigma_{\mathrm{f}}\right)\end{array}$ & $\begin{array}{c}\text { Cold Average } \\
\text { Conductivity } \\
\text { Ratio }\left(\sigma_{\mathrm{m}} / \sigma_{\mathrm{f}}\right)\end{array}$ & $\begin{array}{c}\text { Cold Vertical } \\
\text { Conductivity } \\
\text { Ratio }\left(\sigma_{\mathrm{m}} / \sigma_{\mathrm{f}}\right)\end{array}$ & $\begin{array}{c}\text { Cold Horizontal } \\
\text { Conductivity } \\
\text { Ratio }\left(\sigma_{\mathrm{m}} / \sigma_{\mathrm{f}}\right)\end{array}$ \\
\hline 30 & 0.892 & 1.30 & $1.46 \pm 0.06$ & 1.70 & 1.64 & 1.77 \\
40 & 0.900 & 2.29 & $2.54 \pm 0.18$ & 2.15 & 2.27 & 2.34 \\
50 & 0.863 & 2.19 & $2.54 \pm 0.12$ & 2.70 & 2.02 & 2.05 \\
80 & 0.865 & 3.20 & $3.70 \pm 0.06$ & 2.79 & 2.66 \\
\hline
\end{tabular}

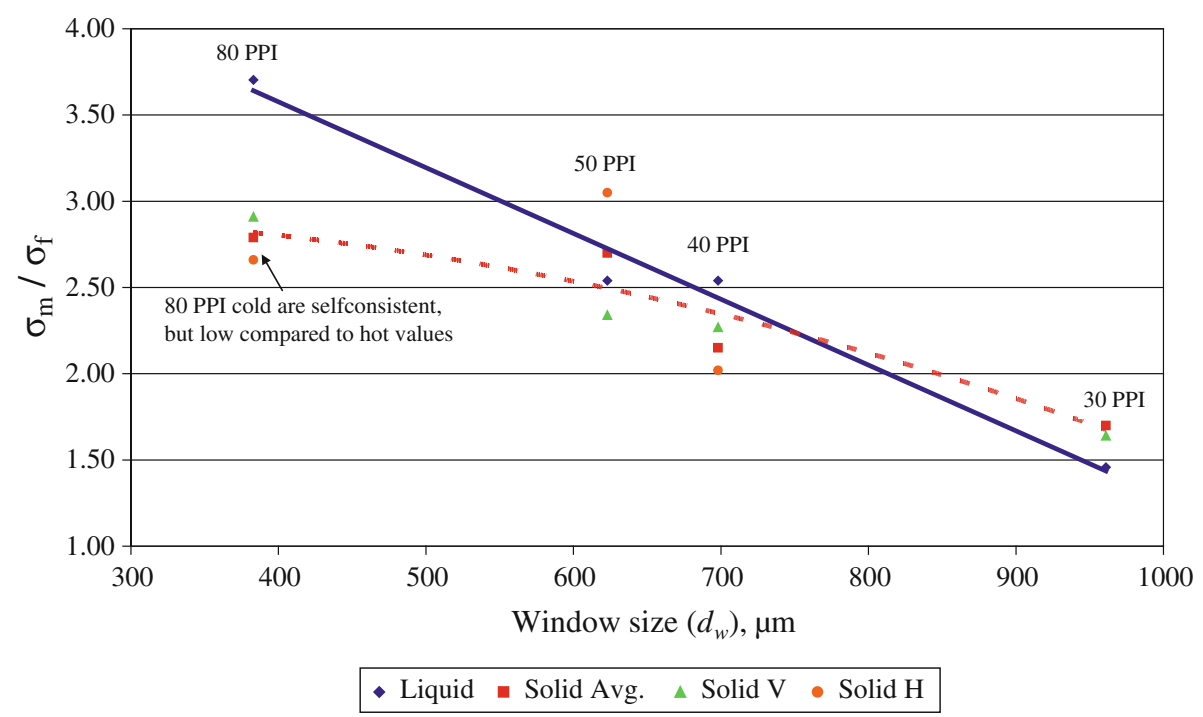

Fig. 8 - Conductivity ratio of metal, $\sigma_{\mathrm{m}}$ and metal-impregnated filter, $\sigma_{\mathrm{f}} v s$. window size, $d_{\mathrm{w}}(\mu \mathrm{m})$. Comparison between liquid metal values fitted to experimental data using FEM and average, vertical, and horizontally cut solid filter sections (cold readings).

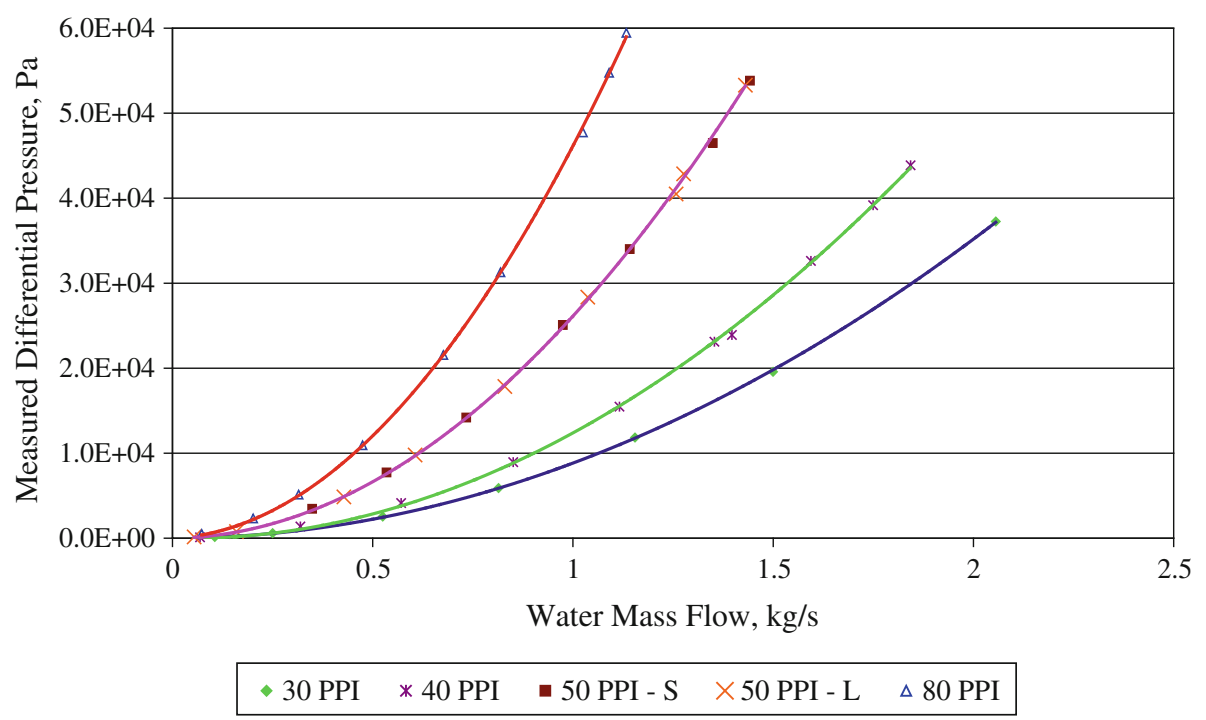

Fig. 9-Ceramic foam filter pressure drop measurements $(\mathrm{Pa})$ as a function of water mass flow (kg/s) for the 101-mm "expanding flow field" filter design. 


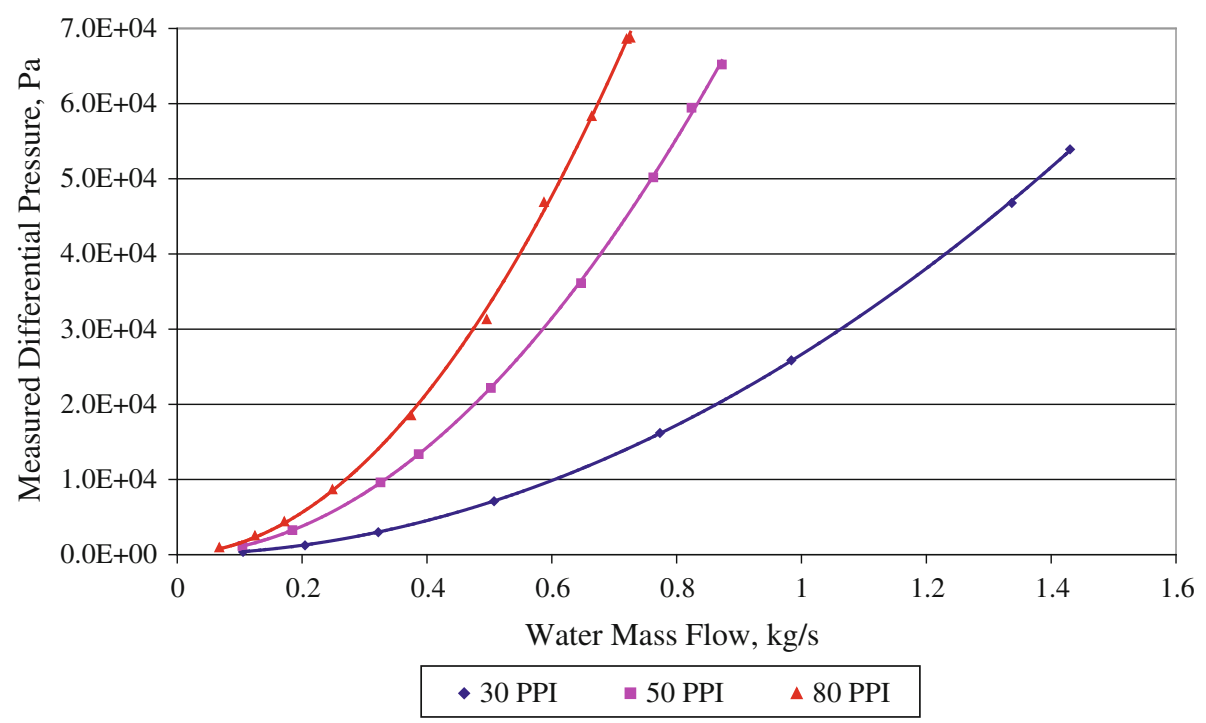

Fig. 10 - Ceramic foam filter pressure drop measurements $(\mathrm{Pa})$ as a function of water mass flow (kg/s) for the 49-mm "straight through" filter design.

Table IV. Empirical Coefficients for Eq. [19]

\begin{tabular}{lcrrr}
\hline $\begin{array}{l}\text { Filter } \\
\text { Type (PPI) }\end{array}$ & $\begin{array}{c}\text { Filter Diameter } \\
(\mathrm{mm})\end{array}$ & $\begin{array}{c}A \\
\text { (Eq. [19]) }\end{array}$ & $\begin{array}{c}B \\
\text { (Eq. [19]) }\end{array}$ & $\begin{array}{c}R^{2} \\
\text { (Eq. [19]) }\end{array}$ \\
\hline 30 & 101 & 8754 & 83.2 & 0.9999 \\
40 & 101 & 13362 & -974.4 & 0.9996 \\
50 & 101 & 25703 & 428.6 & 0.9997 \\
80 & 101 & 44142 & 2017.1 & 0.9998 \\
30 & 49 & 25480 & 1131.9 & 1.0000 \\
50 & 49 & 83965 & 1771.7 & 0.9998 \\
80 & 49 & 129032 & 1960.1 & 0.9994 \\
\hline
\end{tabular}

poorly wets the surface of the ceramic, and in the absence of intense pressure (e.g., 4000 bar for mercury) will not penetrate the micro porosity.

\section{Filter Permeability Measurements, Analytic and FEM Modeling}

Permeability measurements were performed using 101- and 49-mm-diameter filters as shown in Figures 5(a) and (b). Results for these experiments are summarized in Figures 9 and 10. Results are nearly perfectly described by second-order empirical equations of the following form:

$$
\text { Filter Pressure Drop }(\mathrm{Pa})=A \dot{m}^{2}+B \dot{m}
$$

where $A$ and $B$ are empirical constants, and $\dot{m}$ is the measured mass flow rate of water $(\mathrm{kg} / \mathrm{s})$. Values for the coefficients $A$ and $B$ are summarized in Table IV.

The experiments conducted using the $101-\mathrm{mm}$ filters allowed the flow field within the filter element to expand, virtually negating wall effects; however, these experiments did not have a defined flow area, and therefore had no definable velocity for use with Eq. [1]. In order to determine the Forchheimer $k_{1}$ and $k_{2}$ terms using the $101-\mathrm{mm}$ filters, it was necessary to use computational fluid dynamics (CFD) to solve for the flow field. An iterative procedure was applied as described in Figure 11. An "effective" flow field diameter was initially assumed for use with Eq. [1], the resulting $k_{1}$ and $k_{2}$ terms were then used with the CFD model, and the pressure gradients determined. If the results were in error, then a new "effective" diameter was assumed, and the procedure repeated until convergence was achieved. Example flow fields for the 101- and 49-mm diameter filter apparatus at $280 \mathrm{~K}\left(7^{\circ} \mathrm{C}\right)$ and $0.5 \mathrm{~m} / \mathrm{s}$ inlet water velocity are shown in Figures 12(a) and (b), respectively.

Results for the Forchheimer $k_{1}$ and $k_{2}$ terms for the 49- and $101-\mathrm{mm}$ filters are summarized in Table V. More detailed results are given in Appendix Table II. The FEM-estimated $k_{1}$ and $k_{2}$ parameters for the "expanding flow field" $101-\mathrm{mm}$ diameter experiments do not deviate by more than 16 pct from the directly measured "straight through" results for either $k_{1}$ or $k_{2}$.

Excellent agreement was found between the measured pressure gradients and those predicted using $2 \mathrm{D}$ axial symmetric FEM or analytic Eq. [1]. Deviations were in the range of \pm 0 to 7 pct, as plotted in Figures 13 and 14, against the 1:1 diagonal. This level of agreement can be taken as empirical confirmation of the adequateness of the uniform inlet velocity profile assumed in the FEM modeling and the use of the "effective" diameter for the analytic modeling using Eq. [1] of the "expanding flow field" 101-mm filters.

Important confirmation is also evidenced by the lack of variation of the measured pressure gradient between experiments conducted using $50 \mathrm{PPI}, 101-\mathrm{mm}$ diameter filters with the "long" and "short" inlet length configurations and the equivalent 49-mm filter, with the "short" inlet configuration, as shown in Figure 15. This figure verifies that inlet length and variation of the inlet 
Measure: $\Delta P$, Diameter, $L$, Mass Flow,

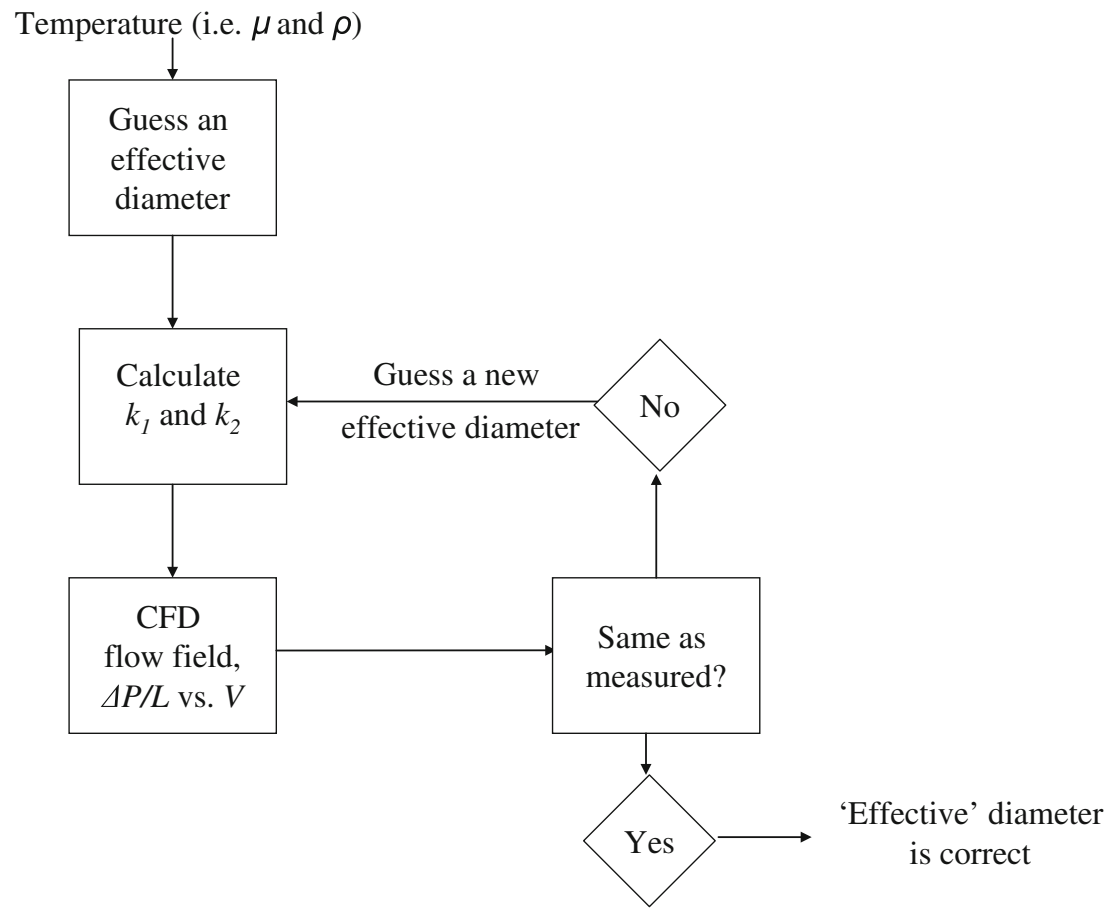

Fig. 11-FEM CFD procedure applied to the 101-mm experimental results to determine the Forchheimer, Eq. [1], parameters $k_{1}$ and $k_{2}$.

condition from laminar to turbulent pipe flow over the range of flow conditions should not have resulted in significant (i.e., measurable) biases to the results.

\section{DISCUSSION ON PERMEABILITY MEASUREMENTS}

\section{A. Forchheimer Eq. [1] Coefficients, $k_{1}$ and $k_{2}$}

Using the apparatus in this study, the pressure resolution during flow was better than $62.5 \mathrm{~Pa}$, i.e., the $0.01 \mathrm{~mA}$ manual verification of automated readings (which had a theoretical resolution of $25 \mathrm{~Pa}$ ), or a gradient uncertainty of $\sim \pm 625 \mathrm{~Pa} / \mathrm{m}$ depending on the sample. $625 \mathrm{~Pa} / \mathrm{m}$ represented $>5$ pct uncertainty at flow rates in the range from 0.03 to $0.08 \mathrm{~m} / \mathrm{s}$, depending on the filter PPI. It has previously been reported that the transition to second-order behavior occurs at $<0.02 \mathrm{~m} / \mathrm{s}$ for 65 and 80 PPI filters similar to those used in these experiments. ${ }^{[5]}$ With the limitations of the apparatus, it was therefore necessary to determine both $k_{1}$ and $k_{2}$ from flow conditions, where both terms were simultaneously significant, i.e., it was not possible to operate in a purely "Darcy" regime.

In order to derive the Forchheimer coefficients in Table V, three procedures were explored:

(a) An "automated" second-order regression, with a zero intercept, using Excel 2003/2010.

(b) Ergun et al.'s procedure of dividing Eq. [1] by the velocity and performing a linear regression. ${ }^{27]}$ (c) An iterative procedure to first guess $k_{1}$ and then correlate the remainder for $k_{2}$ using an exponential regression.

It should be noted that the values for the coefficients $A$ and $B$ summarized in Table IV for Excel $2^{\text {nd }}$-order correlations of the data can be converted to the Forchheimer coefficients through simple mathematical manipulation. This clearly makes the negative coefficient $(B)$ for the 40 PPI physically meaningless, even when $R^{2}=0.9996$.

No physically meaningful correlations could be performed on the values of $k_{1}$ and $k_{2}$ found using Excel, e.g., comparison with total porosity or window size. Better results were obtained following the recommended method of Ergun. The most physically meaningful results (i.e., those with a clear trend) were obtained following the third procedure, where $k_{1}$ was initially guessed, the first-order component of Eq. [1] subtracted from the total and an exponential regression performed on the remainder. When the exponent on the velocity became 2.00000 , the procedure was deemed converged. These are the values of $k_{1}$ and $k_{2}$, previously presented in Table V. $k_{1}$ and $k_{2}$ obtained by all the three methods are summarized in Appendix Table II for reference.

The third procedure appeared to prevent experimental variance from appearing disproportionately in the firstorder $k_{1}$ term. Very small percentage errors in measured pressure at high velocity, represent very large errors when compared with the magnitude of pressure measured at low velocity, given the two orders change in magnitude with velocity, i.e., "small" errors at high velocity can produce large changes in the estimated values for $k_{1}$. 
The $k_{1}$ and $k_{2}$ values from Table $\mathrm{V}$ have been plotted in Figure 16 as functions of the window diameter $d_{\mathrm{w}}$, and more specifically the window area, $\frac{\pi d_{\mathrm{w}}}{4}$. Empirical

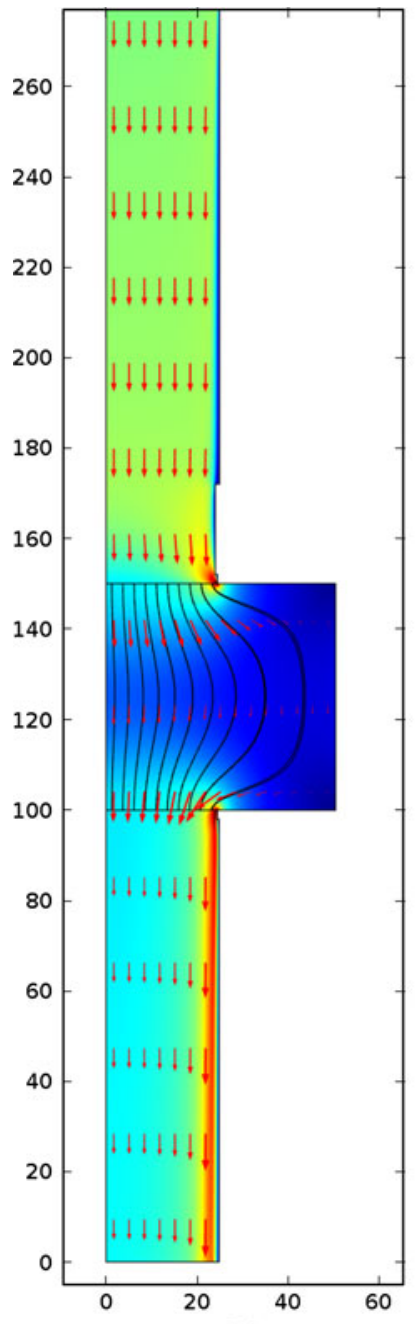

(a)

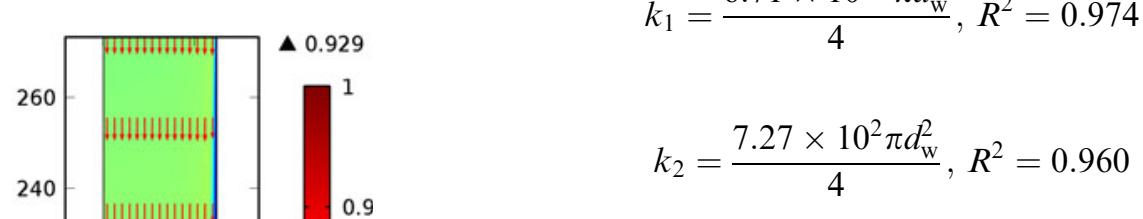

From Figure 16 and Eqs. [20] and [21], it is concluded that from 30 to 80 PPI filters tested in these experiments behave much more like a series of "orifices," than they do a series of struts as is assumed in simple cubic cell ${ }^{[28,29]}$ or more complex dodecahedron ${ }^{[30]}$ and tetrakaidecahedron ${ }^{[9,31,32]}$ models. An examination of Figure 1 would seem to support the concept of "orifices," given the high percentage of closed windows, particularly at higher PPIs. A simple strut model would not appear to be valid for the ceramic foam filters used in this study.

\section{B. Development of the Experimental Method}

Concern with regard to bypassing of the flow around the filters and down the wall of the apparatus was the primary consideration in the design of the filter holder apparatus, as explained in the experimental section. The previous literature provided little guidance on the detailed design of the filter holder or how to produce functional wall sealing arrangements.

A series of incremental improvements were therefore necessary to arrive at the final procedure. The initial "expanding flow field" 101-mm apparatus was operated without wall sealing, and this was found relatively adequate, except at the highest velocity/pressure drops and the "tightest" 80 PPI filters. High flow and tight filters created large driving forces for bypassing.

The use of the "straight through" 49-mm apparatus necessitated the development of adequate wall sealing. High viscosity silicone was initially used alone, but visual observation through the Plexiglas housing showed that the sealant was forced out of the channel at the wall for 50 and 80 PPI filters, particularly during operation at high velocity and high pressure. The loss of seal was verified experimentally by repeating measurements and comparing with the previously "well-sealed" results as

Fig. 12-Comparison of calculated flow fields for 50 PPI filters for the 101-mm "expanding flow field" $(a)$ and 49-mm "straight through" $(b)$ designs, both for $0.5 \mathrm{~m} / \mathrm{s}$ uniform inlet velocity, and $280 \mathrm{~K}\left(7^{\circ} \mathrm{C}\right)$ water temperature, shown with a common $0-1 \mathrm{~m} / \mathrm{s}$ color scale. Pressure gradients of 501.1 and $1612.4 \mathrm{kPa} / \mathrm{m}$ were calculated for these two cases with the "short" inlet $k_{1}$ and $k_{2}$ parameters as shown in Table V.

Table V. Forchheimer Empirical Coefficients for Eq. [1]

\begin{tabular}{|c|c|c|c|c|c|c|c|c|}
\hline $\begin{array}{l}\text { Filter } \\
\text { Type } \\
\text { (PPI) }\end{array}$ & $\begin{array}{c}\text { Actual } \\
\text { Filter } \\
\text { Diameter }(\mathrm{m})\end{array}$ & $\begin{array}{c}\text { Filter } \\
\text { Thickness } \\
L(\mathrm{~m})\end{array}$ & $\begin{array}{c}\text { Water } \\
\text { Temperature } \\
\text { (K) }\end{array}$ & $\begin{array}{c}\text { Water } \\
\text { Density } \rho \\
\left(\mathrm{kg} / \mathrm{m}^{3}\right)\end{array}$ & $\begin{array}{c}\text { Water } \\
\text { Viscosity } \mu \\
(\mathrm{Pa} \cdot \mathrm{s})\end{array}$ & $\begin{array}{l}\text { Eq. [1] } \\
\text { Forchheimer } \\
k_{1}\left(\mathrm{~m}^{2}\right)\end{array}$ & $\begin{array}{c}\text { Eq. [1] } \\
\text { Forchheimer } \\
k_{2}(\mathrm{~m})\end{array}$ & $\begin{array}{c}\text { Inlet } \\
\text { Length (m) }\end{array}$ \\
\hline 30 & 48.7 & 50.7 & 281.4 & 999.9 & $1.330 \mathrm{E}-03$ & $5.08 \mathrm{E}-08$ & $5.46 \mathrm{E}-04$ & 1.0 \\
\hline 30 & 101 & 50.7 & 280.2 & 999.9 & $1.374 \mathrm{E}-03$ & $5.57 \mathrm{E}-08$ & $5.25 \mathrm{E}-04$ & 1.0 \\
\hline 40 & 101 & 47.7 & 279.1 & 999.9 & $1.422 \mathrm{E}-03$ & $3.10 \mathrm{E}-08$ & $3.38 \mathrm{E}-04$ & 1.0 \\
\hline 50 & 49.2 & 49.6 & 280.1 & 999.9 & $1.378 \mathrm{E}-03$ & $1.57 \mathrm{E}-08$ & $1.66 \mathrm{E}-04$ & 1.0 \\
\hline 50 & 101 & 49.6 & 278.9 & 999.9 & $1.426 \mathrm{E}-03$ & $1.71 \mathrm{E}-08$ & $1.69 \mathrm{E}-04$ & 1.0 \\
\hline 50 & 101 & 49.6 & 280.0 & 999.9 & $1.382 \mathrm{E}-03$ & $1.52 \mathrm{E}-08$ & $1.71 \mathrm{E}-04$ & 3.0 \\
\hline 80 & 49.1 & 50.3 & 279.3 & 999.9 & $1.413 \mathrm{E}-03$ & $6.52 \mathrm{E}-09$ & $1.15 \mathrm{E}-04$ & 1.0 \\
\hline 80 & 101 & 50.3 & 280.8 & 999.9 & $1.351 \mathrm{E}-03$ & $5.44 \mathrm{E}-09$ & $9.96 \mathrm{E}-05$ & 1.0 \\
\hline
\end{tabular}




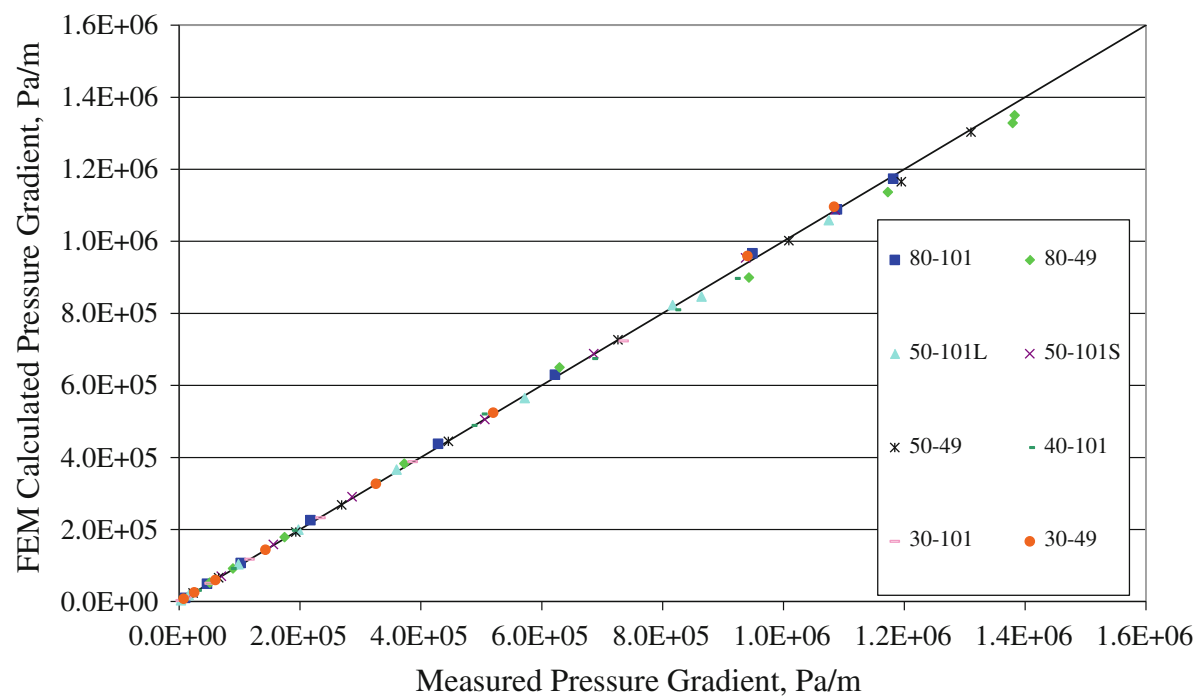

Fig. 13-FEM CFD results for 30 through 80 PPI filters of 101- and 49-mm nominal filter diameters, $L=$ "long" ( $3 \mathrm{~m})$ and $S=$ "short" (1 m) inlet lengths, compared against the experimental pressure gradients $(\mathrm{Pa} / \mathrm{m})$.

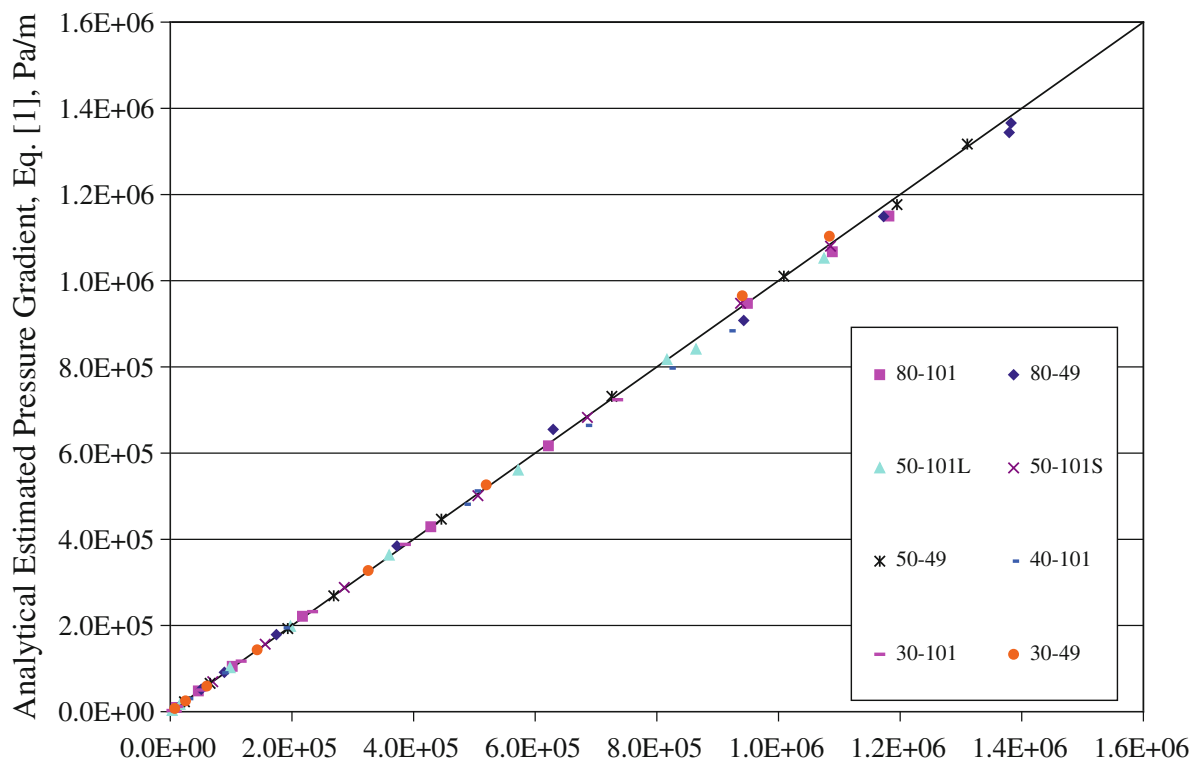

Measured Pressure Gradient, $\mathrm{Pa} / \mathrm{m}$

Fig. 14 -Eq. [1] results for 30 through 80 PPI filters of 101 - and 49-mm nominal filter diameters, $L=$ "long" ( $3 \mathrm{~m})$ and $S=$ "short" (1 m) inlet lengths, compared with the experimental pressure gradients $(\mathrm{Pa} / \mathrm{m})$.

shown in Figure 17 for experiments conducted using the 80 PPI, 49-mm diameter filter.

The final experimental design used water-swollen cellulose and silicone to provide a very low permeability seal, which was not subject to physical removal at pressures of up to 0.8 bar. This was verified both visually and by repeated measurements over the whole pressure range with test filters. Results for the 80 PPI filter using this final procedure, are also presented in Figure 17. It is worth noting that all deviations in the experiments resulted in lower measured pressure gradients, i.e., the highest measured pressure drop and the lowest permeability value for a given filter are most probably the correct values.

Recently, Innocentini et al.$^{[33]}$ discussed the impact of bypassing and flow field expansion on measured pressure drops in metal foam. Examination of the change in pressure drop with filter thickness indicated that wall bypassing reduced the pressure drop and that the measured pressure drop did not increase linearly with larger thickness. It must therefore be assumed that the equipment was operating partially as an "annular orifice" along the wall. The flow field expansion in Innocentini's alternate apparatus design was not 


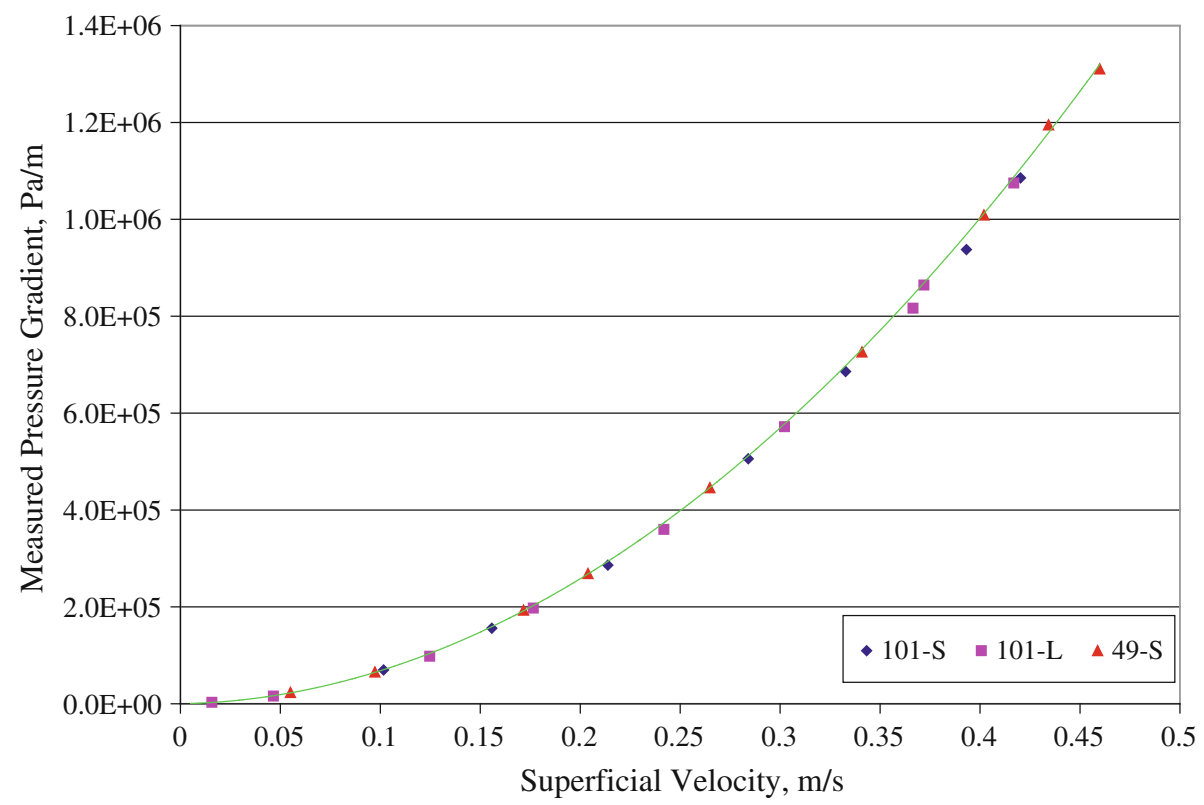

Fig. 15-Comparison between the $L=$ "long" $(3 \mathrm{~m})$ and $S=$ "short" $(1 \mathrm{~m})$ inlet length for the 101-mm and comparison with the 49-mm diameter filter results. Velocities are calculated using an "effective" flow diameter of $66.1 \mathrm{~mm}$, determined by FEM/CFD for the 101-mm diameter filters.

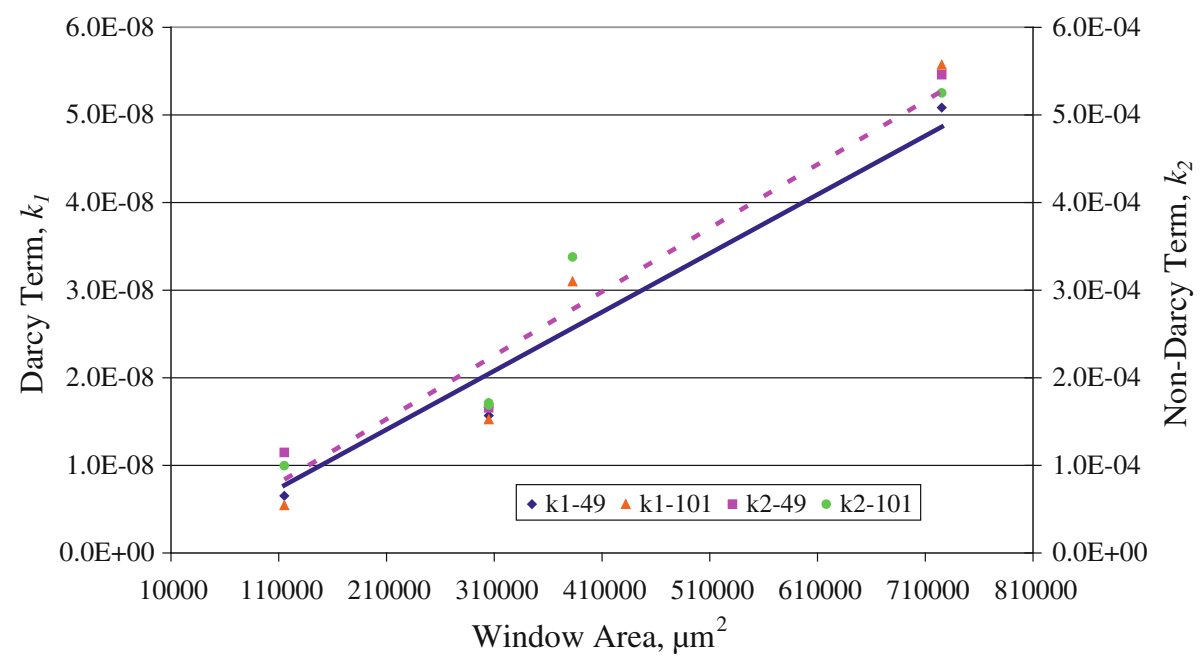

Fig. 16-Correlation of Darcy term, $k_{1}\left(\mathrm{~m}^{2}\right)$ and Non-Darcy term, $k_{2}(\mathrm{~m})$ with window area $\frac{\pi d_{\mathrm{w}}^{2}}{4} \cdot k_{1}$ is correlated by the solid line and $k_{2}$ by the dotted line.

analyzed using CFD, and in both cases, no sealing was indicated at the walls. ${ }^{[33]}$

\section{Correlation of Results, and Comparison with Dietrich and Ergun}

Extensive efforts have been made to correlate the obtained results and compare with previously published equations. Of the previously published equations, only the equation of Dietrich, Eq. [8], was found to adequately describe the data. This comparison is made for the 30, 50, and 80 PPI, "straight through" 49-mm results shown in Figure 18. Agreement is considered as adequate being typically within \pm 50 pct (except at low velocity), i.e., it achieves a similar accuracy for foams, as the original Ergun equation achieves for packed beds.

Other equations were found to underestimate dramatically the measured pressure drops obtained using the final and "well-sealed" experimental procedure. Most previously published equations did describe the obtained results for the "straight through" experiments in the absence of a wall seal or the "expanding flow field" results in the absence of area correction. No firm conclusions can be drawn from these facts, as details on the sealing arrangements and analysis techniques used in previous studies are generally lacking. 


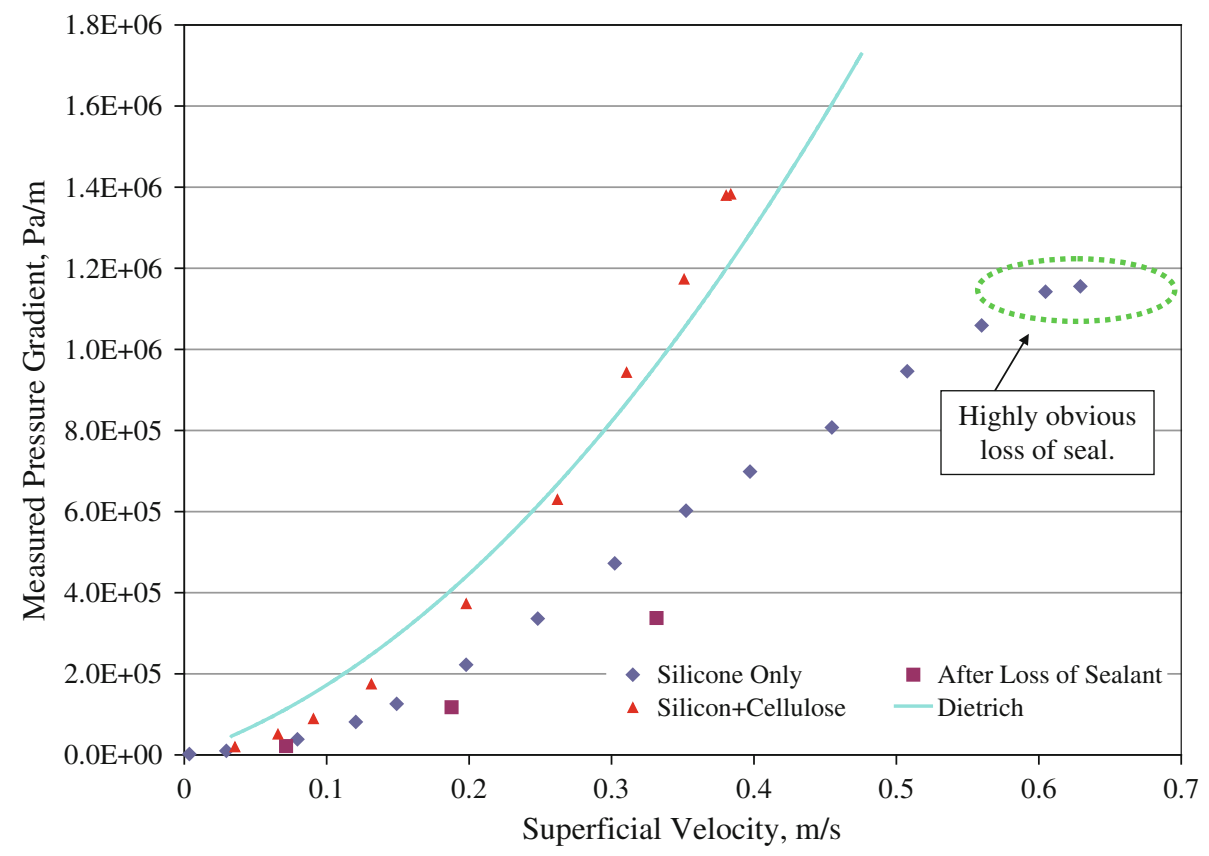

Fig. 17-Impact of sealing method and loss of seal on measured pressure gradients for 49-mm diameter "straight through" design using an 80 PPI filter element as a function of water superficial velocity. Comparison is made with Dietrich's equation [8]. ${ }^{[10,11]}$

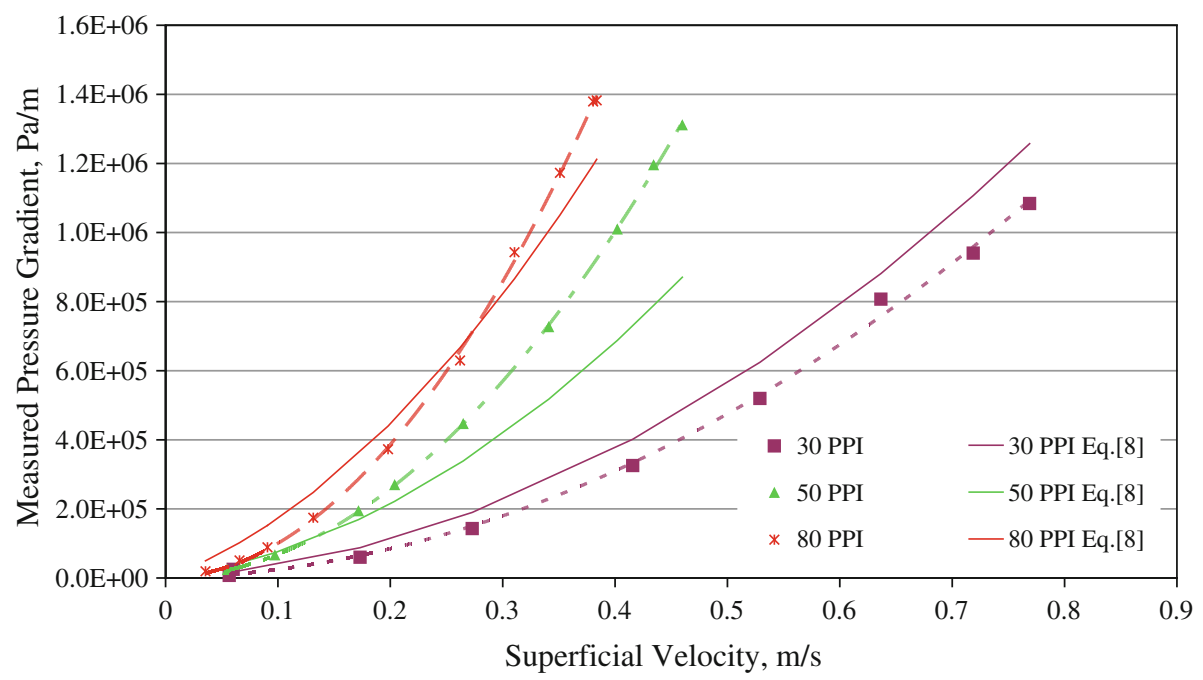

Fig. 18 - Comparison between Dietrich's Eq. [8] ${ }^{[10,11]}$ and measured data for the 49-mm diameter "straight through" 30,50 , and 80 PPI filters' measured data. Experimental data are plotted with dotted lines and symbols, Dietrich's predictions are plotted as solid lines.

The best empirical correlation obtained was a slightly modified version of Ergun's equation. ${ }^{[7]}$

$\frac{\Delta P}{L}=8.385\left(150 \frac{(1-\varepsilon)^{2}}{\varepsilon^{3}} \frac{\mu V}{D_{\mathrm{w}}^{2}}+1.75 \frac{(1-\varepsilon) \rho}{\varepsilon^{3}} \frac{\rho V^{2}}{D_{\mathrm{w}}}\right), R^{2}=0.95$

Equation [22] is plotted in Figure 19, along with the +30 and -30 pct lines.

Equation [22] is equivalent to using 23.4 and 2.00 (based on an average $\varepsilon=0.88$ ), as the empirical constants, instead of the values 110 and 1.45 in Dietrich's Eq. [8] or the Ergun equivalent values of 66.7 and 1.17 from Eq. [7]:

$$
\frac{\Delta P}{L}=23.4 \frac{\mu V_{\mathrm{s}}}{\varepsilon d_{\mathrm{h}}^{2}}+2.00 \frac{\rho V_{\mathrm{s}}^{2}}{\varepsilon^{2} d_{\mathrm{h}}}
$$

Applying Eq. [23] to the obtained data indicates a significant reduction in error compared with the original Eq. [8], particularly at low velocity and pressure and an overall reduction in average error from $\sim 40$ pct to 


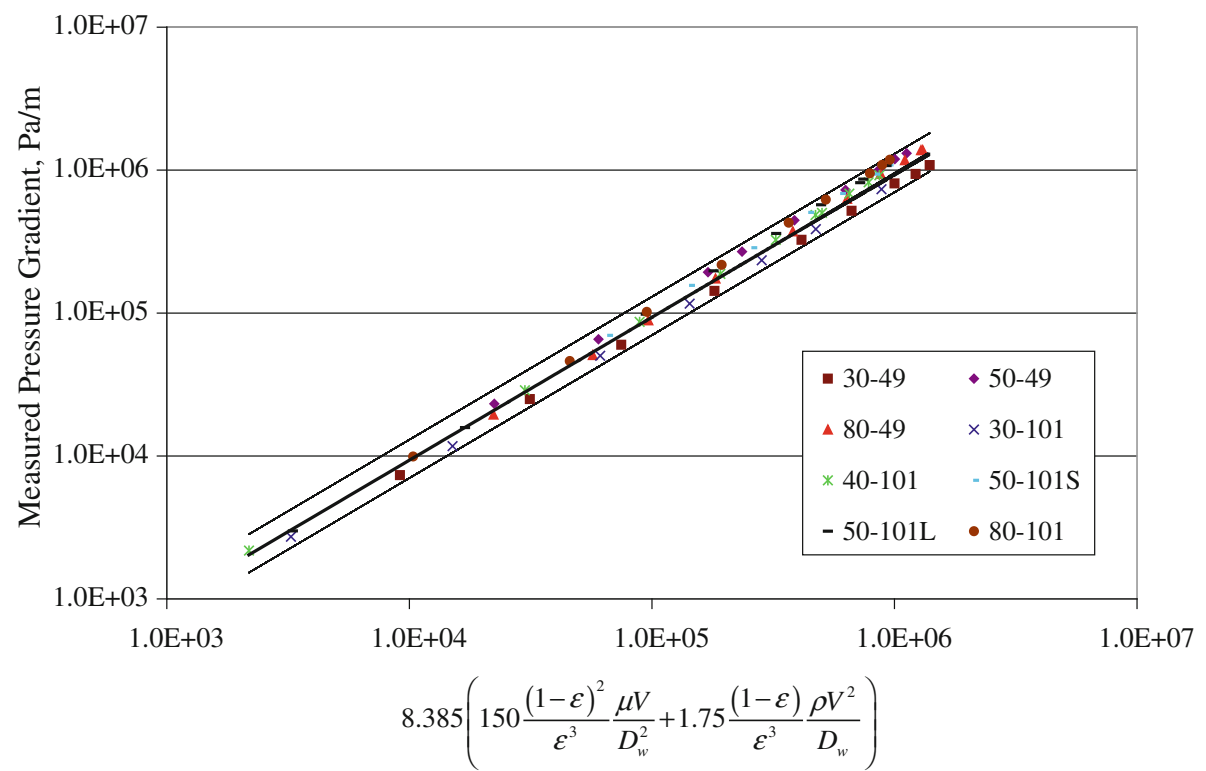

Fig. 19-Overall correlation Eq. [22], comparison with the measured pressure gradients ranging from 30 to 80 PPI filter elements. 49-mm diameter measurements were not available for the 40 PPI filters, as the filter exhibited poor mechanical properties and disintegrated on cutting. The upper and lower lines in the figure indicate a range of \pm 30 pct.

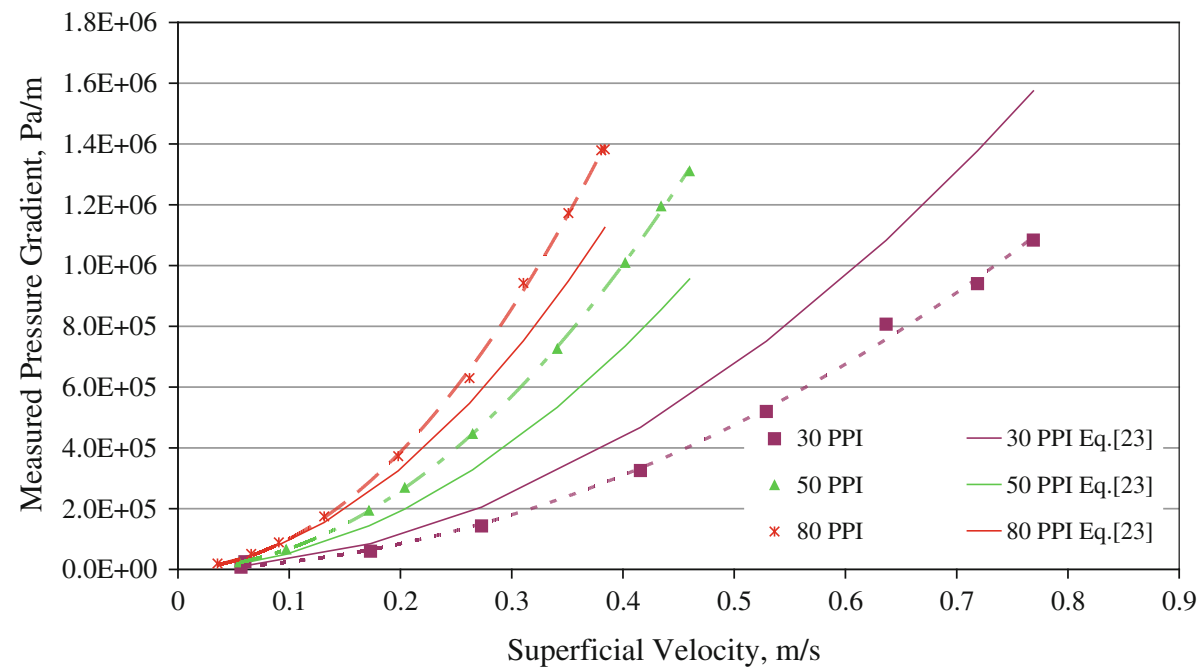

Fig. 20 - Comparison of the modified Dietrich Eq. [23] with experimental data for the 49-mm diameter "straight through" experimental results from the 30,50 , and 80 PPI filters.

$\sim 30$ pet. Equation [23] is plotted against the 30,50 , and 80 PPI, "straight through" 49-mm results in Figure 20.

Attempts were made to use cell diameter, $d_{\mathrm{c}}$, strut diameter, $d_{\mathrm{s}}$, and tortuosity, $\tau$, in various correlations; however, no improvement could be made over the accuracy of Eqs. [23], [22], or [8].

\section{Comments Regarding CFD Modeling}

The CFD models presented here are discussed in more detail elsewhere. ${ }^{[34]}$ Some pertinent points to achieving adequate agreement between FEM, analytic models and measured values are as follows: (a) Iteration between high-quality measurements and FEM to ensure validity of assumptions and accuracy of final models.

(b) Correct and validated boundary conditions, e.g., no-slip walls, contiguous velocity fields between liquid and porous media domains, and the inlet velocity profile.

(c) Use of the low Reynolds number $k$ - $\varepsilon$, and Reynolds Averaged Navier-Stokes (RANS) model for turbulence $\left(k_{0}=0.005 \mathrm{~m}^{2} / \mathrm{s}^{2}\right.$ and $\left.\varepsilon_{0}=0.005 \mathrm{~m}^{2} / \mathrm{s}^{3}\right)$, to adequately cover the difficult range of velocities in the inlet region.

(d) Use of dense meshes in regions of high velocity gradients (e.g., boundary mesh at the "no-slip" walls). 
(e) Precise measurement and exact geometric reproduction of the actual apparatus.

It is important to note that if significant bypassing had occurred during these experiments, it would not have been possible to achieve agreement between the CFD model and the experimental data for the 49-mm filter design. The agreement between the CFD results and the 49-mm and, subsequently that between the 49$\mathrm{mm}$ and the 101-mm designs, are taken as confirmation that the wall-sealing arrangements in fact were of negligible permeability.

\section{CONCLUSIONS}

Pressure gradients in CFFs have been found to correlate against velocity with high precision at both low and high velocities, using the Forchheimer equation, Eq. [1]. Forchheimer first-order $k_{1}$ and second-order $k_{2}$ terms were both found to correlate directly with the measured mean window area for each filter type $(30,40$, 50, and $80 \mathrm{PPI})$.

The obtained pressure drops in this study could be best estimated using the measured total porosity $\varepsilon$, the optically determined window size $d_{\mathrm{w}}$, and either Dietrich's original equation, Eq. [8], a modified version of Dietrich's equation, Eq. [23], or a slightly modified Ergun equation [22].

Bypassing along the wall must be prevented if accurate permeabilities of CFFs are to be measured using water flow experiments.

If the diameter of the filter is larger than the diameter of the pipe, then CFD must be used to analyze the impact of the expansion of the flow field on the measured pressure drop, i.e., to determine the effective flow field diameter for use with Eq. [1].

Care must be taken while determining how results are mathematically correlated to prevent small percentage errors with the large pressure drops at high velocity from producing too much "noise" in the determination of first-order empirical coefficients for use with the Forchheimer equation, Eq. [1].

\section{FUTURE STUDY}

Experiments should be conducted to elucidate the change of filter pressure drop with filter thickness. This would provide further validation that wall bypassing has been prevented by the current experimental procedures and/or determine the impact of bypassing on measured filter permeabilities.

Additional experiments should be conducted with filters produced from different suppliers and with other filter pore densities, to attempt to improve upon the Dietrich/modified Dietrich equations presented above.

Additional experiments could be conducted with a low range, from 0 to 0.1 bar pressure transducer, at low velocity (0 to $0.05 \mathrm{~m} / \mathrm{s})$, to study the Darcy and transitional regions in greater detail.

The conductivity of metals is best known and can be most easily measured at room temperature. It is recommended that for future tortuosity measurements, impregnate and then cool and solidify the sample. Solid samples can then be machined to precise tolerances, and inductive heating experiments can then be conducted at room temperature and low frequency to determine the tortuosity. Water cooling can even be applied to directly measure the quantity of heat produced and allow operation at steady-state thermal conditions, as has been applied elsewhere. ${ }^{[35]}$

\section{ACKNOWLEDGMENTS}

The current study was carried out as part of the RIRA (Remelting and Inclusion Refining of Aluminium) project funded by the Norwegian Research Council (NRC)—BIP Project No. 179947/I40. The industrial partners involved in the project are Hydro Aluminium AS, SAPA Heat Transfer AB, Alcoa Norway ANS, Norwegian University of Science and Technology (NTNU), and SINTEF Materials and Chemistry. The funds granted by the industrial partners and the NRC are gratefully acknowledged. The authors wish to express their gratitude to Egil Torsetnes at NTNU for helping with the design and construction of the experimental apparatus. Sincere gratitude is also due to Kurt Sandaunet at SINTEF for his support and help, as well as for the use of the SINTEF laboratory.

\section{APPENDIX}

See Appendix Tables I and II. 
Appendix Table I. Tortuosity Experimental Data and FEM Calculated Conductivity Ratios

\begin{tabular}{|c|c|c|c|c|c|}
\hline $\begin{array}{l}\text { Filter } \\
\text { Type (PPI) }\end{array}$ & $\begin{array}{c}\text { Average Metal } \\
\text { Temperature }(\mathrm{K})\end{array}$ & $\begin{array}{c}\text { Estimated Hot } \\
\text { Metal Conductivity } \\
\text { Using Eq. [14] (ohm m) })^{-1}\end{array}$ & $\begin{array}{l}\text { Experimental } \\
\text { Current (A) }\end{array}$ & $\begin{array}{l}\text { Experimental } \\
\text { Power (W) }\end{array}$ & $\begin{array}{l}\text { FEM Estimate } \\
\text { of Conductivity } \\
\text { Ratio }\left(\sigma_{\mathrm{m}} / \sigma_{\mathrm{f}}\right)\end{array}$ \\
\hline 30 & 947 & $3.70 \mathrm{E}+06$ & 716.9 & 1462 & 1.50 \\
\hline 30 & 1000 & $3.58 \mathrm{E}+06$ & 728.0 & 1469 & 1.51 \\
\hline 30 & 1048 & $3.50 \mathrm{E}+06$ & 517.7 & 764 & 1.42 \\
\hline 30 & 995 & $3.60 \mathrm{E}+06$ & 371.2 & 404 & 1.40 \\
\hline \multicolumn{5}{|c|}{ Room temperature final metal conductivity: 60.0 pct IACS, \pm 0.2 pct, 6 counts } & 1.46 \\
\hline 40 & 940 & $3.34 \mathrm{E}+06$ & 628.5 & 790 & 2.75 \\
\hline 40 & 1026 & $3.09 \mathrm{E}+06$ & 628.7 & 836 & 2.42 \\
\hline 40 & 1033 & $3.17 \mathrm{E}+06$ & 629.0 & 827 & 2.45 \\
\hline \multicolumn{5}{|c|}{ Room temperature final metal conductivity: 54.0 pct IACS, \pm 0.8 pct, 48 counts } & 2.54 \\
\hline \multicolumn{6}{|c|}{ Likely $\mathrm{Fe}$ or $\mathrm{Si} \mathrm{Al}$ alloy contamination from melting crucible or metal skimming tool } \\
\hline 50 & 933 & $3.78 \mathrm{E}+06$ & 728.3 & 1078 & 2.67 \\
\hline 50 & 957 & $3.73 \mathrm{E}+06$ & 727.8 & 1105 & 2.54 \\
\hline 50 & 983 & $3.68 \mathrm{E}+06$ & 728.0 & 1059 & 2.65 \\
\hline 50 & 1021 & $3.60 \mathrm{E}+06$ & 728.2 & 1053 & 2.61 \\
\hline 50 & 1044 & $3.56 \mathrm{E}+06$ & 729.2 & 1039 & 2.63 \\
\hline 50 & 1052 & $3.54 \mathrm{E}+06$ & 632.7 & 840 & 2.38 \\
\hline 50 & 1044 & $3.56 \mathrm{E}+06$ & 632.7 & 854 & 2.34 \\
\hline 50 & 1032 & $3.58 \mathrm{E}+06$ & 634.0 & 820 & 2.50 \\
\hline \multicolumn{5}{|c|}{ Room temperature final metal conductivity: 61.0 pct IACS, \pm 0.5 pct, 66 counts } & 2.54 \\
\hline 80 & 948 & $3.68 \mathrm{E}+06$ & 732.4 & 831 & 3.75 \\
\hline 80 & 954 & $3.66 \mathrm{E}+06$ & 732.9 & 832 & 3.74 \\
\hline 80 & 963 & $3.65 \mathrm{E}+06$ & 733.6 & 852 & 3.60 \\
\hline 80 & 972 & $3.62 \mathrm{E}+06$ & 733.4 & 814 & 3.80 \\
\hline 80 & 979 & $3.61 \mathrm{E}+06$ & 733.1 & 823 & 3.72 \\
\hline 80 & 985 & $3.60 \mathrm{E}+06$ & 733.1 & 823 & 3.71 \\
\hline 80 & 991 & $3.59 \mathrm{E}+06$ & 732.9 & 832 & 3.63 \\
\hline 80 & 994 & $3.58 \mathrm{E}+06$ & 732.9 & 817 & 3.72 \\
\hline 80 & 997 & $3.58 \mathrm{E}+06$ & 733.0 & 827 & 3.66 \\
\hline \multicolumn{5}{|c|}{ Room temperature final metal conductivity: 59.7 pct IACS, \pm 0.4 pct, 37 counts } & 3.70 \\
\hline
\end{tabular}




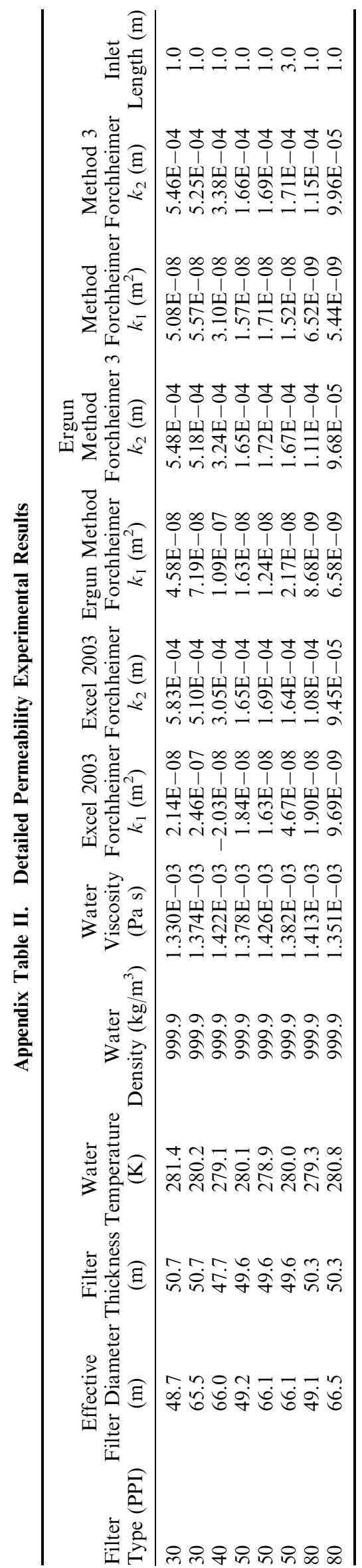

\section{REFERENCES}

1. M. J. Pryor: US Patent 3,893,917, 1975.

2. M.W. Kennedy, S. Akhtar, J.A. Bakken, and R.E. Aune: Metall. Mater. Trans. B, in press.

3. M.W. Kennedy, S. Akhtar, J.A. Bakken, and R.E. Aune: Light Metals, San Diego, CA, 27 February to 3 March, 2011, pp. 76368

4. Sivex ${ }^{\circledR}$ Application Guidelines, Jan-10-E4-565.

5. B. Hübschen, J. Krüger, J. Keegan, and W. Schneider, Light Metals, 2000, pp. 809-15.

6. P. Forchheimer: Z. Ver. Deutsch. Ing, 1901, vol. 45, pp. 1782-88.

7. S. Ergun: Chem. Eng. Prog., 1952, vol. 48, pp. 89-94.

8. I. Macdonald, M. El-Sayed, K. Mow, and F. Dullien: Ind. Eng. Chem. Fundam., 1979, vol. 18, pp. 199-208.

9. J. Richardson, Y. Peng, and D. Remue: Appl. Catal. A, 2000, vol. 204, pp. 19-32.

10. B. Dietrich, W. Schabel, M. Kind, and H. Martin: Chem. Eng. Sci., 2009, vol. 64, pp. 3633-40.

11. B. Dietrich: Chem. Eng. Sci., 2012, vol. 74, pp. 192-99.

12. S.A. Shakiba, R. Ebrahimi, and M. Shams: J. Fluids Eng., 2011, vol. 133, pp. 111105-1-10.

13. M.W. Kennedy, R. Fritzsch, S. Akhtar, J.A. Bakken, and R.E. Aune: U.S. Provisional Patent Application 61/639,196, 2012.

14. J. Große, B. Dietrich, H. Martin, M. Kind, J. Vicente, and E.H. Hardy: Chem. Eng. Technol., 2008, vol. 31, pp. 307-14.

15. B. Dietrich, G.I. Garrido, P. Habisreuther, N. Zarzalis, H. Martin, M. Kind, and B. Kraushaar-Czarnetzki: Ind. Eng. Chem. Res., 2009, vol. 48, pp. 10395-401.

16. Copper Wire Tables Circular No. 31: US Bureau of Standards, 1913, pp. 1-76.

17. R. Fritzsch, M.W. Kennedy, S. Akhtar, J.A. Bakken, and R.E. Aune, Electromagnetic Processing of Materials, 23-25 October, Beijing, China, 2012, pp. 1-4.

18. P. Desai, H. James, and C. Ho: J. Phys. Chem. Ref. Data, 1984, vol. 13, pp. 1131-72.

19. M.W. Kennedy, S. Akhtar, J.A. Bakken, and R.E. Aune, COMSOL Users Conference, 26-28 October, Stuttgart, Germany, 2011, pp. 1-9.

20. M.W. Kennedy, S. Akhtar, J.A. Bakken, and R.E. Aune, Light Metals, Orlando, Florida, 3-7 March, 2012, pp. 269-75.

21. L.F. Moody: Trans. ASME, 1944, vol. 66, pp. 671-84.

22. W. Zhi-qing: Appl. Math. Mecha., 1982, vol. 3, pp. 433-46.

23. F.M. White, Fluid Mechanics, 4th ed., McGraw Hill, Boston, 1999, pp 331-32.

24. N. Keegan, W. Schneider, and H. Krug, Light Metals, 1999, pp. 1031-41.

25. E. Moreira, M. Innocentini, and J. Coury: J. Eur. Ceram. Soc., 2004, vol. 24, pp. 3209-18.

26. G. Diedericks and J.Du. Plessis: Adv. Water Resour., 1996, vol. 19, pp. 225-39.

27. S. Ergun and A.A. Orning: Ind. Eng. Chem., 1949, vol. 41, pp. 1179-84.

28. T. Lu, H. Stone, and M. Ashby: Acta Mater., 1998, vol. 46, pp. 3619-35.

29. M. Lacroix, P. Nguyen, D. Schweich, C.Pham. Huu, S. SavinPoncet, and D. Edouard: Chem. Eng. Sci., 2007, vol. 62, pp. 325967.

30. T.T. Huu, M. Lacroix, C.Pham. Huu, D. Schweich, and D. Edouard: Chem. Eng. Sci., 2009, vol. 64, pp. 5131-42.

31. M.V. Twigg and J.T. Richardson: Ind. Eng. Chem. Res., 2007, vol. 46 , pp. $4166-77$.

32. A. Inayat, J. Schwerdtfeger, H. Freund, C. Körner, R.F. Singer, and W. Schwieger, Chem. Eng. Sci., 2011, vol. 66 (12), pp. 275863.

33. M.D.M. Innocentini, L. Lefebvre, R. Meloni, and E. Baril: J. Porous Mater., 2010, vol. 17, pp. 491-99.

34. M.W. Kennedy, R. Fritzsch, J.A. Bakken, and R.E. Aune: Presented at COMSOL ${ }^{\circledR}$ User's Conference, Milan, Italy, 10-12 October, 2012, pp. 1-7.

35. M.W. Kennedy, S. Akhtar, J.A. Bakken, and R.E. Aune, 3rd International Symposium on High Temperature Processing, Orlando, Florida, 3-7 March, 2012, pp. 373-82. 